\title{
Insight into the origin of carbon matrix effects on the emission signal of atomic lines in inductively coupled plasma optical emission spectrometry
}

\author{
Raquel Serrano, Guillermo Grindlay *, Luis Gras, Juan Mora \\ University of Alicante, Department of Analytical Chemistry, Nutrition and Food Sciences, PO Box 99, 03080 Alicante, Spain
}

\section{A R T I C L E I N F O}

\section{Keywords:}

Carbon

Charge transfer

Matrix effects

Inductively coupled plasma

Optical emission spectrometry

\begin{abstract}
A B S T R A C T
In inductively coupled plasma optical emission spectrometry (ICP-OES), the presence of carbon in the matrix strongly affects (positively and negatively) the emission signal of atomic lines. However, the emission signal of ionic lines is mostly unaffected by this concomitant. The goal of this work is to gain insight into the origin of carbon matrix effects on the signal of atomic lines in ICP-OES. To this end, the emission signal of a total of 3608 lines (i.e., 1755 atomic and 1853 ionic lines) of 62 elements (Ag, Al, As, Au, B, Ba, Be, Ca, Cd, Ce, Co, Cr, Cs, Cu, Dy, Er, Eu, Fe, Ga, Gd, Ge, Hg, Ho, I, In, Ir, K, La, Li, Lu, Mg, Mn, Mo, Na, Nb, Nd, Ni, P, Pb, Pd, Pr, Pt, Re, Rh, S, $\mathrm{Sb}, \mathrm{Sc}$, Se, Sm, Sn, Sr, Tb, Te, Th, Ti, Tm, U, V, Y, Yb, Zn and Zr) were registered for carbon containing solutions $\left(20 \mathrm{~g} \mathrm{~L}^{-1}\right.$ ) prepared from glycerol. Results were compared to those obtained operating a $1 \% \mathrm{w} \mathrm{w}^{-1} \mathrm{HNO}_{3} \mathrm{so}^{-}$ lution. Compared to the $\mathrm{HNO}_{3}$ reference solution, emission signals for As, B, $\mathrm{Hg}, \mathrm{I}, \mathrm{P}$, Se and Te atomic lines were increased for the carbon containing solution. However, signal suppression was noticed for the signal emission of $\mathrm{Ag}, \mathrm{Al}, \mathrm{Ba}, \mathrm{Be}, \mathrm{Ca}, \mathrm{Cd}$, Co, Cr, Cs, Eu, Fe, Ga, Ge, K, Ho, In, La, Li, Lu, Mg, Mn, Mo, Na, Nb, Ni, Pb, Pd, Pr, Pt, Re, $\mathrm{Rh}, \mathrm{S}, \mathrm{Sb}, \mathrm{Sc}, \mathrm{Sn}, \mathrm{Sr}, \mathrm{Ti}, \mathrm{Tm}, \mathrm{V}, \mathrm{Y}$ and $\mathrm{Zr}$ atomic lines. No measurable matrix effects within experimental uncertainties were registered for $\mathrm{Au}, \mathrm{Cu}, \mathrm{Ir}, \mathrm{Gd}$ and $\mathrm{Zn}$ atomic lines. As regards $\mathrm{Ce}, \mathrm{Dy}, \mathrm{Er}, \mathrm{Nd}, \mathrm{Sm}, \mathrm{Tb}, \mathrm{Th}, \mathrm{U}$ and $\mathrm{Yb}$ no clear conclusion about matrix effects was feasible due to the limited atomic emission wavelengths monitored. Experimental results showed that the intensity of matrix effects depends on both analyte ionization energy and the energy of the electronic upper level involved in the electronic transition. Matrix effects on atomic emission lines can be explained by the simultaneous occurrence of different mechanisms: (i) charge transfer reactions; (ii) collisional ionization; and (iii) collisional excitation with carbon-based species. Because these mechanisms mostly affect analyte atomic population, carbon matrix effects are more significant on the emission signal of atomic lines rather than ionic ones. Finally, the judicious analyte wavelength selection is critical to minimize carbon matrix effects for those elements for which the most sensitive wavelength is atomic (i.e., Se and alkali elements). On this regard, the selection of the internal standard should consider both the ionization energy and the energy of the electronic upper level of the analyte.
\end{abstract}

\section{Introduction}

The analysis of carbon containing matrices by means of inductively coupled plasma optical emission spectrometry (ICP-OES) and inductively coupled plasma mass spectrometry (ICP-MS) is challenging due to the occurrence of both spectral and non-spectral interferences $[1,2]$. The origin of spectral interferences is well understood and could be mitigated by means of different instrumental and non-instrumental approaches [1-4]. Carbon based non-spectral interferences (i.e., matrix effects) are, however, more complex since aerosol generation and transport to the plasma, plasma energy, analyte excitation and ionization mechanisms and, as regards ICP-MS, ion extraction, can be simultaneously affected [1,2]. Most of the studies about carbon based non-spectral interferences have been focused on the influence of organic solvents on aerosol generation and transport, plasma characteristics and ion extraction. In general, organic solvents afford finer aerosol and higher aerosol transport than diluted acid solutions [5]. Consequently, analyte signal is expected to increase. Nevertheless, because of solvent load into the plasma also increases, plasma temperature may be deteriorated affecting negatively to the analyte signal (i.e., signal suppression) [6-9]. In general, the magnitude of carbon matrix effects in ICPbased techniques depends on several factors such as: (i) the element

\footnotetext{
* Corresponding author.

E-mail address: guillermo.grindlay@ua.es (G. Grindlay).
} 
considered; (ii) the carbon matrix source and concentration; and (iii) the instrument characteristics and experimental conditions employed (i.e., r.f. power, nebulizer gas flow rate, etc.) [6-13]. More limited has been the number of works dealing with changes on analyte excitation/ionization mechanisms due to the presence of carbon in ICP-based techniques.

Allain et al. [14] first noticed that the ion signal for several hard-toionize elements in ICP-MS was selectively enhanced operating carboncontaining matrices (i.e., glycerol, methanol, methane, etc.). Thus, for instance, $\mathrm{Hg}$ signal was enhanced 5-fold in the presence of a $1 \mathrm{~mol} \mathrm{~L}^{-1}$ glycerol solution regarding a non-carbon containing standard. Subsequent investigations demonstrated that analyte signal enhancement was related to the occurrence of a charge transfer (CT) mechanism between analyte atoms $(\mathrm{M})$ and carbon charged species (i.e., mainly $\mathrm{C}^{+}$) that increases the production of excited ions from the original atom $\left(\left(\mathrm{M}^{+}\right)^{*}\right)$ $[6-9,15]$ :

$C^{+}+M \rightarrow \mathrm{C}+\left(\mathrm{M}^{+}\right)^{*}$

This reaction is a two-electron transfer process, one electron from the analyte atom is transferred to the ion and another electron from the analyte atom is excited to a higher level. Unlike other mechanisms present in the ICP discharge, carbon-based CT reaction is highly specific since it requires minimum reaction energy defect (i.e., difference between carbon ionization energy and a given ionic electronic level of the analyte) and conservation of total electron spin [8,16-18]. This mechanism explains the rather limited number of elements affected by this interference (i.e., As, $\mathrm{Au}, \mathrm{Hg}, \mathrm{I}, \mathrm{P}, \mathrm{Se}, \mathrm{Sb}$ and Te) [8]. Nevertheless, carbon-based CT reactions in ICP-MS are not yet fully understood since, despite reaction requirements are fulfilled, ionic signal for several hardto-ionize elements (i.e., B, Os, Pt, Ir, Cd Be and S) is not enhanced operating carbon containing matrices [8]. This interference does not affect the ionic signal of those elements with ionization energies below $8.0 \mathrm{eV}$ since they are almost totally ionized under normal ICP experimental conditions.

Carbon-based CT reactions also affect the analyte emission profile in ICP-OES. It has been observed that the emission signal for As, Hg, I, P, Se and $\mathrm{Te}$ atomic lines is enhanced operating carbon containing matrices, regardless of the view mode employed [10-13]. Signal enhancement is more pronounced for those lines which electronic transitions involve the highest upper atomic energy levels. Thus, for instance, operating a $20 \mathrm{~g}$ $\mathrm{L}^{-1} \mathrm{C}$ solution, relative intensity of As I $173.950 \mathrm{~nm} \mathrm{(}{ }^{2} \mathrm{D}_{5 / 2}(8.48 \mathrm{eV}) \rightarrow$ $\left.{ }^{2} \mathrm{D}_{5 / 2}(1.35 \mathrm{eV})\right)$ and As I $249.294 \mathrm{~nm}\left({ }^{4} \mathrm{P}_{1 / 2}(6.28 \mathrm{eV}) \rightarrow{ }^{2} \mathrm{D}_{3 / 2}(1.31 \mathrm{eV})\right)$ were increased 1.56 and 1.27, respectively [12]. Carbon-induced signal enhancement on the emission of atomic lines has been successfully explained by means of a two-step mechanism based on carbon CT reactions followed by an ion-electron recombination process by which analyte ions $\left(\left(\mathrm{M}^{+}\right)^{*}\right)$ are transformed in excited atoms $\left(\mathrm{M}^{*}\right)$ [10-12]:

$$
\mathrm{C}^{+}+M \rightarrow C+\left(\boldsymbol{M}^{+}\right)^{*} \text { Carbon - based CT }
$$

$\left(M^{+}\right)^{*}+e^{-} \rightarrow M^{*} \quad$ Ion - electron recombination

Because the increase in the analyte excited ionic population $\left(\left(\mathrm{M}^{+}\right)^{*}\right)$, higher ionic emission signals should be expected for As, $\mathrm{Hg}, \mathrm{I}, \mathrm{P}, \mathrm{Se}$ and Te operating carbon-rich matrices but, except for $\mathrm{Hg}$, it has not been feasible to check it due to several experimental constraints [12]. Our research group [10,12] and others [11,13,19] have previously reported that the emission signal for atomic lines of a significant number of elements (e.g. Ag, Al, Au, B, Ba, Be, Ca, Cd, Co, Cr, Cu, Fe, Ga, In, Ir, K, Li, $\mathrm{Mg}, \mathrm{Mn}, \mathrm{Na}, \mathrm{Ni}, \mathrm{Pb}, \mathrm{Pd}, \mathrm{Pt}, \mathrm{S}, \mathrm{Sb}, \mathrm{Sr}$ and $\mathrm{Zn}$ ) is suppressed when operating carbon containing solutions, particularly for those wavelengths with total emission line excitation energies lower than $4-5 \mathrm{eV}[10,12]$. Interestingly, the emission of ionic lines for these elements were unaffected by carbon. To explain signal suppression effects on the emission of atomic lines, different mechanisms, such as carbide formation or collisional deactivation by carbon atoms, have been proposed $[10,11,19]$. However, none of them successfully explain the different behavior shown by atomic and ionic lines in the presence of carbon matrices in ICP-OES. Therefore, an extended and systematic study of the influence of carbon on the behavior of atomic lines in ICP-OES is strongly required to clarify this relevant subject.

The goal of this work was to gain insight into the origin of carbon matrix effects on the emission signal of atomic lines in ICP-OES. To this end, the emission signal of a total of 1755 atomic lines of 62 elements (Ag, Al, As, Au, B, Ba, Be, Ca, Cd, Ce, Co, Cr, Cs, Cu, Dy, Er, Eu, Fe, Ga, Gd, Ge, Hg, Ho, I, In, Ir, K, La, Li, Lu, Mg, Mn, Mo, Na, Nb, Nd, Ni, P, Pb, Pd, Pr, Pt, Re, Rh, S, Sb, Sc, Se, Sm, Sn, Sr, Tb, Te, Th, Ti, Tm, U, V, Y, Yb, $\mathrm{Zn}$ and $\mathrm{Zr}$ ) were registered for carbon containing solutions $\left(20 \mathrm{~g} \mathrm{~L}^{-1}\right.$ prepared from glycerol) and results were compared to those obtained for a $1 \% \mathrm{w} \mathrm{w}^{-1} \mathrm{HNO}_{3}$ solution. For a better understanding of carbon matrix effects, the emission signal of a total of 1853 ionic lines for the abovementioned elements was also monitored. Finally, considering the findings of this study, it was examined how to detect and mitigate carbon matrix effects on the emission of atomic lines.

\section{Experimental}

\subsection{Reagents}

High-purity water with a resistivity $>18 \mathrm{M} \Omega \mathrm{cm}$ obtained from a Milli-Q water Direct-Q3 purification system (Millipore Inc., Paris, France) was used to prepare the solutions employed throughout this work. Nitric acid $\left(69 \% \mathrm{w} \mathrm{w}^{-1}\right)$ was employed to prepare the reference solution (Panreac, Castellar del Valles, Spain) whereas matrixcontaining solutions were made from 86 to $88 \% \mathrm{w} \mathrm{w}^{-1}$ glycerol (Scharlau, Sentmenat, Spain) and $99.95 \% \mathrm{w} \mathrm{w}^{-1}$ calcium nitrate tetrahydrate (Merck, Darmstadt, Germany). Mono-elemental $1000 \mathrm{mg} \mathrm{L}^{-1}$ analyte solutions (Ag, Al, As, Au, B, Ba, Be, Ca, Cd, Co, Cr, Cu, Fe, Ga, Ge, $\mathrm{Hg}$, I, In, Ir, K, Mg, Mn, Mo, Na, Nb, Ni, P, Pb, Pd, Pt, Re, Rh, Sb, Sc, Se, $\mathrm{Sn}, \mathrm{Sr}, \mathrm{Te}, \mathrm{Ti}, \mathrm{V}, \mathrm{Y}, \mathrm{Zn}$ and $\mathrm{Zr}$ ), lithium and caesium nitrates and lanthanide chloride salts $\left(\mathrm{HoCl}_{3}, \mathrm{TbCl}_{3}, \mathrm{TmCl}_{3}, \mathrm{PrCl}_{3}\right)$ were purchased from Sigma-Aldrich (Schelldorf, Germany). A $10 \mathrm{mg} \mathrm{L}^{-1}$ rare earth elements multielemental standard (Ce, Dy, Er, Eu, Gd, Ho, La, Lu, Nd, Pr, Sc, Sm, Tb, Th, Tm, Y, Yb, U) was obtained from High Purity Standards (North Charleston, SC, USA). Sulfuric acid $96 \% \mathrm{w} \mathrm{w}^{-1}$ was purchased from Panreac (Castellar del Valles, Spain).

\subsection{Matrix and analyte solutions}

To evaluate the influence of carbon on the analytical signal, a $20 \mathrm{~g}$ $\mathrm{L}^{-1}$ carbon containing solution prepared from glycerol was employed whereas a $1 \% \mathrm{w} \mathrm{w}^{-1} \mathrm{HNO}_{3}$ was used as the reference matrix solution. Glycerol was used as carbon source since a $20 \mathrm{~g} \mathrm{~L}^{-1}$ carbon solution from this compound affords similar aerosol and plasma characteristics than those from a $1 \% \mathrm{w} \mathrm{w}^{-1} \mathrm{HNO}_{3}$ one because both solutions present similar physical properties (i.e., surface tension, density, and volatility) [10]. Thus, it is easier to study the influence of carbon on the mechanisms responsible of analyte emission in ICP-OES $[10,12]$. On this regard, to gain insight into carbon matrix effects, additional experiments were performed with both matrices spiked with calcium at two concentration levels (2000 and 20,000 $\mathrm{mg} \mathrm{L}^{-1}$ ).

The analyte concentration employed in this work was selected according to the sensitivity of the emission lines of the elements evaluated. Thus, mono-elemental solutions containing $200 \mathrm{mg} \mathrm{L}^{-1}$ of analyte were prepared for most of the elements (Ag, Al, As, $\mathrm{Au}, \mathrm{B}, \mathrm{Be}, \mathrm{Cd}, \mathrm{Co}, \mathrm{Cr}, \mathrm{Cu}$, Fe, Ga, Ge, Hg, I, In, Ir, Mn, Mo, Nb, Ni, P, Pb, Pd, Pt, Re, Rh, Sb, Sc, Se, $\mathrm{Sn}, \mathrm{Te}, \mathrm{Ti}, \mathrm{V}, \mathrm{Y}, \mathrm{Zn}$ and $\mathrm{Zr}$ ), while for those elements whose emission lines are more sensitive, solutions containing $100 \mathrm{mg} \mathrm{L}^{-1}$ (Ho, Pr, Tm and $\mathrm{Tb}$ ) and $50 \mathrm{mg} \mathrm{L}^{-1}$ (Ba, Ca, Cs, K, Li, Mg Na and $\mathrm{Sr}$ ) were prepared. Matrix effects for $\mathrm{La}, \mathrm{Ce}, \mathrm{Nd}, \mathrm{Sm}, \mathrm{Eu}, \mathrm{Gd}, \mathrm{Dy}, \mathrm{Er}, \mathrm{Yb}, \mathrm{Lu}, \mathrm{Th}$ and $\mathrm{U}$ were investigated using $1 \mathrm{mg} \mathrm{L}^{-1}$ standard due to the concentration constrains imposed by the standard available. Finally, due to the limited sensitivity of the atomic lines of S in ICP-OES, a solution containing $1000 \mathrm{mg} \mathrm{L}^{-1}$ of this element made from sulfuric acid was used. 


\subsection{ICP instrumentation}

ICP-OES measurements were performed using an Agilent 720 ICPOES (Agilent, Santa Clara, USA) with axial viewing. The sample introduction system consisted of a OneNeb ${ }^{\circledR}$ concentric pneumatic nebulizer (Ingeniatrics, Sevilla, Spain) coupled to a cyclonic spray chamber (Cinnabar, Glass Expansion, Australia). Table 1 shows the operating conditions used. Under these experimental conditions (i. e. high r.f. power and low nebulizer gas flow rate), it is easier to evaluate carbon influence on analyte excitation/ionization mechanisms since plasma temperature is hardly affected by the introduction of glycerol solutions $[10,12]$.

All the (ionic and atomic) wavelengths investigated throughout this work are included in the Appendix (Tables S1 and S2, respectively). Spectroscopic data were obtained from the NIST database [20] and some other sources [21-23]. For those elements present in the rare earth elements multielemental standard (La, Ce, Nd, Sm, Eu, Gd, Dy, Er, Yb, Lu, Th and $\mathrm{U}$ ), and given the impossibility to measure emission lines for the different element independently, wavelengths were carefully selected to avoid potential spectral interferences after a thoroughly revision of spectral database [20-23]. Wavelengths not totally resolved by ICP-OES spectrometer were discarded.

No significant carbon-based spectral interferences were found for the (ionic and atomic) wavelengths monitored operating the $20 \mathrm{~g} \mathrm{~L}^{-1}$ carbon containing solution prepared from glycerol. In all cases, raw emission signals were corrected with a blank solution using ICP-OES instrument software. Signal-to-background ratios were, for all the lines tested in this work, above 10 to clearly distinguish analyte emission signal from the background at the concentrations employed.

\subsection{Determination of carbon concentration in real samples}

To evaluate the impact of the carbon-based matrix interferences from a practical point of view, different real samples were considered: mussel tissue (BCR-278R), fly ash (BCR-176R), polyethylene (high level) (ERMEC681K) and seagrass samples (i.e., Cymodocea nodosa (Ucria) Aschers and Posidonia oceanica (L.) Delile). All samples were digested using a microwave oven (model Start D, Milestone, S.r.l., Sorisole, Italy) using a mixture of $\mathrm{HNO}_{3}\left(69 \% \mathrm{w} \mathrm{w}^{-1}\right)$ and $\mathrm{H}_{2} \mathrm{O}_{2}\left(30 \% \mathrm{w} \mathrm{v}^{-1}\right)$ and the different programmes recommended by the manufacturer (Table S3, Appendix). Carbon content in the digested samples were determined by ICP-OES using the C I $193.030 \mathrm{~nm}$ line and glycerol standards (i.e., 2-20 g $\left.\mathrm{L}^{-1} \mathrm{C}\right)[10]$.

\section{Results}

\subsection{Carbon matrix effects}

To investigate carbon matrix effects in ICP-OES, ionic and atomic analyte emission signals for a $20 \mathrm{~g} \mathrm{~L}^{-1}$ carbon containing solution were registered and results were compared to those obtained for a $1 \% \mathrm{w} \mathrm{w}^{-1}$ $\mathrm{HNO}_{3}$ one (reference solution). Relative emission intensity, $\mathrm{I}_{\text {rel }}$, defined

Table 1

ICP-OES operating conditions.

\begin{tabular}{|c|c|}
\hline Plasma forward power (W) & 1400 \\
\hline \multicolumn{2}{|l|}{ Argon flow rate $\left(\mathrm{L} \mathrm{min}^{-1}\right)$} \\
\hline Plasma & 15 \\
\hline Auxiliary & 1.5 \\
\hline Nebulizer $\left(Q_{g}\right)$ & 0.7 \\
\hline Sample uptake rate $\left(Q_{L}\right)\left(m L \min ^{-1}\right)$ & 0.6 \\
\hline \multicolumn{2}{|l|}{ Sample introduction system: } \\
\hline Nebulizer & OneNeb $\mathbb{R}$ \\
\hline Spray chamber & Cyclonic \\
\hline View mode & Axial \\
\hline Integration time (s) & 1 \\
\hline Replicates & 3 \\
\hline
\end{tabular}

as the net signal intensity of the analyte obtained in the carboncontaining solution relative to that in the $1 \% \mathrm{w} \mathrm{w}^{-1} \mathrm{HNO}_{3}$ one, was calculated for a total of 3608 emission lines (1853 ionic and 1755 atomic) of 62 elements (Ag, Al, As, Au, B, Ba, Be, Ca, Cd, Ce, Co, Cr, Cs, $\mathrm{Cu}, \mathrm{Dy}, \mathrm{Er}, \mathrm{Eu}, \mathrm{Fe}, \mathrm{Ga}, \mathrm{Gd}, \mathrm{Ge}, \mathrm{Hg}$, Ho, I, In, Ir, K, La, Li, Lu, Mg, Mn, Mo, $\mathrm{Na}, \mathrm{Nb}, \mathrm{Nd}, \mathrm{Ni}, \mathrm{P}, \mathrm{Pb}, \mathrm{Pd}$, Pr, Pt, Re, Rh, S, Sb, Sc, Se, Sm, Sn, Sr, Tb, Te, $\mathrm{Th}, \mathrm{Ti}, \mathrm{Tm}, \mathrm{U}, \mathrm{V}, \mathrm{Y}, \mathrm{Yb}, \mathrm{Zn}$ and $\mathrm{Zr}$ ). It is important to point out that no ionic emission lines were monitored for As, I, P, Se and Te because their very low sensitivity in the operating wavelength range of the instrument employed [12].Taking into account the average precision of the emission signal for all emission lines tested (approximately 2\%), it can be considered that $\mathrm{I}_{\text {rel }}$ values between 0.96 and 1.04 range indicate no measurable matrix effects within experimental uncertainties. For $\mathrm{I}_{\text {rel }}$ values outside this range, the carbon containing solution gives rise to matrix effects (signal enhance for $\mathrm{I}_{\text {rel }}>1.04$, or signal depression for $\mathrm{I}_{\text {rel }}$ $<0.96)[10,12]$.

In general, no measurable matrix effects within experimental uncertainties were noticed for most ( $>90 \%$ ) of the ionic lines studied in this work (Table S1, Appendix). For those ionic lines showing matrix effects, slight signal suppression (i.e., $0.91<\mathrm{I}_{\text {rel }}<0.95$ ) was registered with some few exceptions (e.g. Al II $176.334 \mathrm{~nm}, \mathrm{I}_{\text {rel }} 0.76 \pm 0.03$ ). Ionic lines showing signal suppression correspond to $\mathrm{Al}, \mathrm{Cr}, \mathrm{Fe}, \mathrm{Ge}, \mathrm{Mg}, \mathrm{Ni}, \mathrm{Pb}$, $\mathrm{Rh}, \mathrm{Sc}$ and Ti. Nevertheless, the number of ionic lines showing no measurable matrix effects for these elements was higher than those showing signal suppression. These results are in agreement with previous data in the literature $[10,12]$ and are the expected since neither analyte transport nor plasma temperature are significantly affected by the $20 \mathrm{~g} \mathrm{~L}^{-1}$ carbon containing solution made from glycerol regarding $1 \% \mathrm{w} \mathrm{w}^{-1} \mathrm{HNO}_{3}$. In this work, the Ar I $430.010 \mathrm{~nm}$ line to Ar continuum ratio was employed as an indicator of plasma electron temperature [24]. No significant differences in this ratio were noticed between the glycerol and the reference solution (i.e., Glycerol: $15.5 \pm 0.3 ; 1 \% \mathrm{w} \mathrm{w}^{-1} \mathrm{HNO}_{3}$ : $15.6 \pm 0.2$ ). Finally, signal enhancement was just found for a single $\mathrm{Hg}$ wavelength (i.e., Hg II $194.227 \mathrm{~nm}, \mathrm{I}_{\text {rel }} 1.20 \pm 0.03$ ). This behavior has been previously attributed to changes on $\mathrm{Hg}$ ionic population by carbonbased CT reactions [12].

The behavior of atomic lines was, however, more complex since most of the wavelengths monitored shown matrix effects (Table S2, Appendix). Signal enhancement (i.e., $\mathrm{I}_{\text {rel }}>1.04$ ) was registered for As, B, Hg, I, $\mathrm{P}, \mathrm{Se}$ and Te atomic lines. For these elements, the highest $\mathrm{I}_{\text {rel }}$ values were afforded by Se (e.g. Se I $199.446 \mathrm{~nm}, \mathrm{I}_{\text {rel }} 1.56 \pm 0.02$ ). Negative matrix effects (i.e., signal suppression) were observed for $\mathrm{Ag}, \mathrm{Al}, \mathrm{Ba}, \mathrm{Be}, \mathrm{Ca}, \mathrm{Cd}$, $\mathrm{Co}, \mathrm{Cr}, \mathrm{Cs}, \mathrm{Eu}, \mathrm{Fe}, \mathrm{Ga}, \mathrm{Ge}, \mathrm{K}, \mathrm{Ho}, \mathrm{In}, \mathrm{La}, \mathrm{Li}, \mathrm{Lu}, \mathrm{Mg}, \mathrm{Mn}, \mathrm{Mo}, \mathrm{Na}, \mathrm{Nb}, \mathrm{Ni}$, $\mathrm{Pb}, \mathrm{Pd}, \mathrm{Pt}, \mathrm{Pr}, \mathrm{Re}, \mathrm{Rh}, \mathrm{S}, \mathrm{Sb}, \mathrm{Sc}, \mathrm{Sn}, \mathrm{Sr}, \mathrm{Ti}, \mathrm{Tm}, \mathrm{V}, \mathrm{Y}$ and $\mathrm{Zr}$ atomic lines. Among them, the lowest $\mathrm{I}_{\text {rel }}$ values were shown by La I $510.624 \mathrm{~nm}$ ( $\mathrm{I}_{\text {rel }}$ $0.63 \pm 0.02)$ and Pr I $492.460 \mathrm{~nm}\left(\mathrm{I}_{\text {rel }} 0.62 \pm 0.02\right)$. No carbon matrix effects were registered for $\mathrm{Au}, \mathrm{Cu}, \mathrm{Gd}$, Ir and $\mathrm{Zn}$ atomic lines. Finally, no clear conclusion about matrix effects was feasible for Ce, Dy, Er, Nd, Sm, $\mathrm{Tb}, \mathrm{Th}, \mathrm{U}$ and $\mathrm{Yb}$ atomic lines since the most sensitive emission wavelengths for these elements were ionic and the number of atomic lines available in the ICP-OES employed in this work was rather limited (or even inexistent). Consequently, these elements were not further investigated. Fig. 1 summarizes the influence of the carbon matrix on the signal of the atomic emission lines for the 62 elements investigated.

\subsubsection{Influence of atomic emission line properties on matrix effects}

Previous works by Machat et al. [6], and by our research group $[10,12]$ pointed out that signal enhancement for As (as well as for elements such as $\mathrm{P}$, Se and Te) operating carbon containing solutions strongly depends on the energy of the electronic upper level ( $\left.\mathrm{E}_{\text {upper level }}\right)$ involved in the electronic transition. Therefore, it would be interesting to check whether the emission of atomic lines for other elements behaves similarly. Fig. 2 shows $\mathrm{I}_{\text {rel }}$ values for As, V and Zn atomic lines according to their $\mathrm{E}_{\text {upper level. }}$ These elements were selected to represent the groups of elements exhibiting different matrix effects in the presence of carbon (Fig. 1) and attending to their high number of atomic lines 


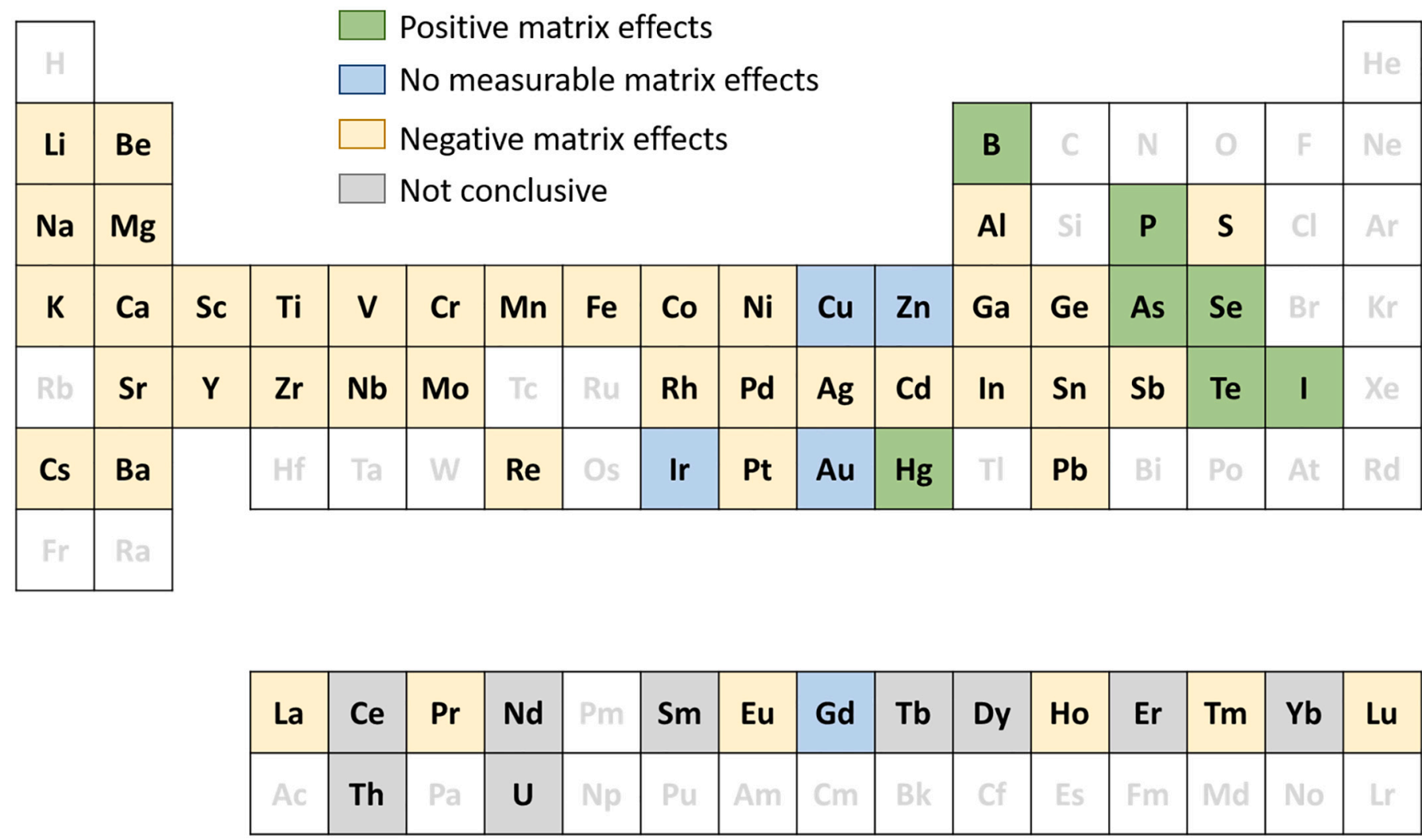

Fig. 1. Response of the atomic lines of the different elements to carbon matrix effects in ICP-OES.

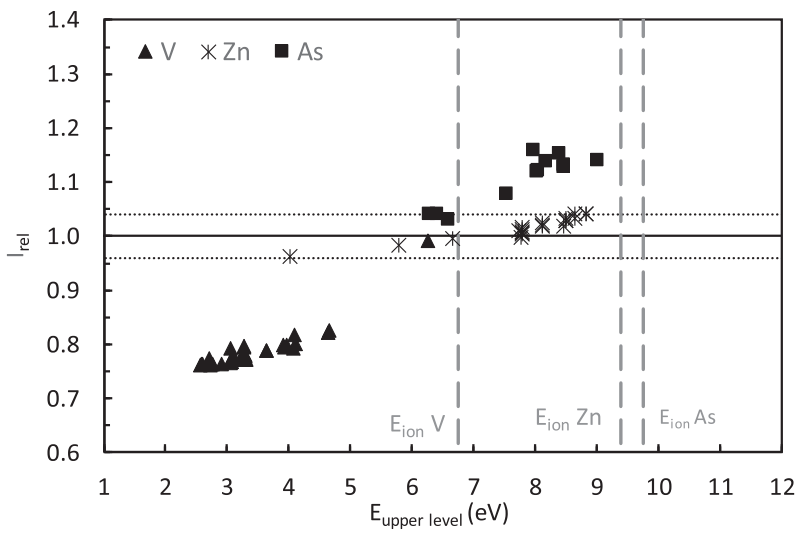

Fig. 2. Relative signal intensity $\left(\mathrm{I}_{\text {rel }}\right)$ obtained for a glycerol solution $\left(20 \mathrm{~g} \mathrm{~L}^{-1} \mathrm{C}\right.$ solution) in comparison to $1.0 \% \mathrm{w} \mathrm{w}^{-1}$ nitric acid for atomic lines according to their electronic upper energy level $\left(E_{\text {upper level }}\right)$. $I_{\text {rel }}$ values among horizontal dotted lines indicate no measurable matrix effects within the experimental uncertainties.

available. Thus, As was selected as an element showing signal enhancement, whereas V and Zn were selected to represent those elements affording signal suppression and no-matrix effects, respectively. Results for the remaining elements investigated in this work can be found in the Appendix (Fig. S1-S3). As expected [10,12], matrix effects for As atomic lines increase with $\mathrm{E}_{\text {upper level }}$ (i.e., higher $\mathrm{I}_{\text {rel }}$ values). Similar findings were also observed for $\mathrm{P}$, Se and Te atomic lines. However, no influence of $\mathrm{E}_{\text {upper level }}$ on $\mathrm{I}_{\text {rel }}$ were registered for $\mathrm{B}, \mathrm{Hg}$ and I (Fig. S1, Appendix). On the other hand, it was also noticed that matrix effects for $\mathrm{V}$ atomic lines decreased with the $\mathrm{E}_{\text {upper level. }}$. For this element,

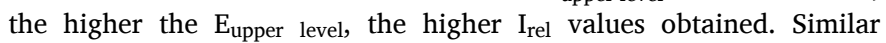
behavior is shown by $\mathrm{Ba}, \mathrm{Ca}, \mathrm{Cr}, \mathrm{Ho}, \mathrm{In}, \mathrm{Li}, \mathrm{Mg}, \mathrm{Mn}, \mathrm{Mo}, \mathrm{Nb}, \mathrm{Pd}, \mathrm{Re}, \mathrm{Rh}$,
$\mathrm{Sb}, \mathrm{Sc}, \mathrm{Sr}, \mathrm{Ti}, \mathrm{Tm}, \mathrm{V}, \mathrm{Y}$ and $\mathrm{Zr}$ atomic lines (Fig. S2.A, Appendix). Interestingly, there were 13 elements belonging to the $\mathrm{V}$ group (i.e., $\mathrm{Ag}$, $\mathrm{Al}, \mathrm{Be}, \mathrm{Cd}, \mathrm{Co}, \mathrm{Fe}, \mathrm{Ga}, \mathrm{Ge}, \mathrm{Ni}, \mathrm{Pb}, \mathrm{Pt}, \mathrm{S}$ and $\mathrm{Sn}$ ) that did not show this trend. Atomic emission lines intensity for these elements was supressed by carbon but no influence of $E_{\text {upper level }}$ on $\mathrm{I}_{\text {rel }}$ was noticed (Fig. S2.B, Appendix). Finally, because the limited number of atomic lines available, no conclusion about the influence of $E_{\text {upper level }}$ on matrix effects was feasible for Cs, Eu, K, La, Lu, Na, and Pr (Fig. S2.C, Appendix). No measurable matrix effects within experimental uncertainties were registered for $\mathrm{Zn}$ atomic lines, regardless the atomic line tested. Similar findings were observed for $\mathrm{Au}, \mathrm{Cu}, \mathrm{Ga}$ and Ir (Fig. S3, Appendix).

\subsubsection{Influence of element ionization energy on matrix effects}

It has been previously reported in ICP-MS that the magnitude of carbon matrix effects is somehow related to analyte $\mathrm{E}_{\text {ion }}$ [8]. Data in Fig. 2 also suggest such relationship, the lowest $\mathrm{I}_{\text {rel }}$ values (0.76-0.99) were observed for $\mathrm{V}\left(\mathrm{E}_{\text {ion }} 6.7 \mathrm{eV}\right)$ and the highest $\mathrm{I}_{\text {rel }}$ values (1.03-1.16) were registered for As $\left(E_{\text {ion }} 9.8 \mathrm{eV}\right)$. To validate this hypothesis, the influence of $E_{\text {ion }}$ on $I_{\text {rel }}$ values was examined using a box plot graph for all the elements investigated (Fig. 3) but Ce, Dy, Er, Nd, Sm, Tb, Th, U and $\mathrm{Yb}$ due to carbon matrix effects ambiguity. Data in Fig. 3 shows that strongest signal suppression corresponded to elements with low $\mathrm{E}_{\text {ion }}$ values (i.e., those that are almost completely ionized in the plasma). When increasing $E_{i o n}$, signal suppression was less severe and either positive or no measurable matrix effects within experimental uncertainties was found among hard-to-ionize elements (i.e., those present in the plasma with low ionization degree, e.g. $52 \%$ for As, $33 \%$ for Se, etc.) (Fig. S4, Appendix) [25]. It is important to note that, irrespective of the element considered, the maximum and upper outliers in the box plot corresponded to those wavelengths involving electronic levels with the highest $\mathrm{E}_{\text {upper level }}$ studied. Because $\mathrm{I}_{\text {rel }}$ values for those electronic transitions involving the highest $\mathrm{E}_{\text {upper level }}$ were significantly different from the average behavior shown by the remaining transitions, matrix effects were indeed related to analyte ionic and atomic population abundance 


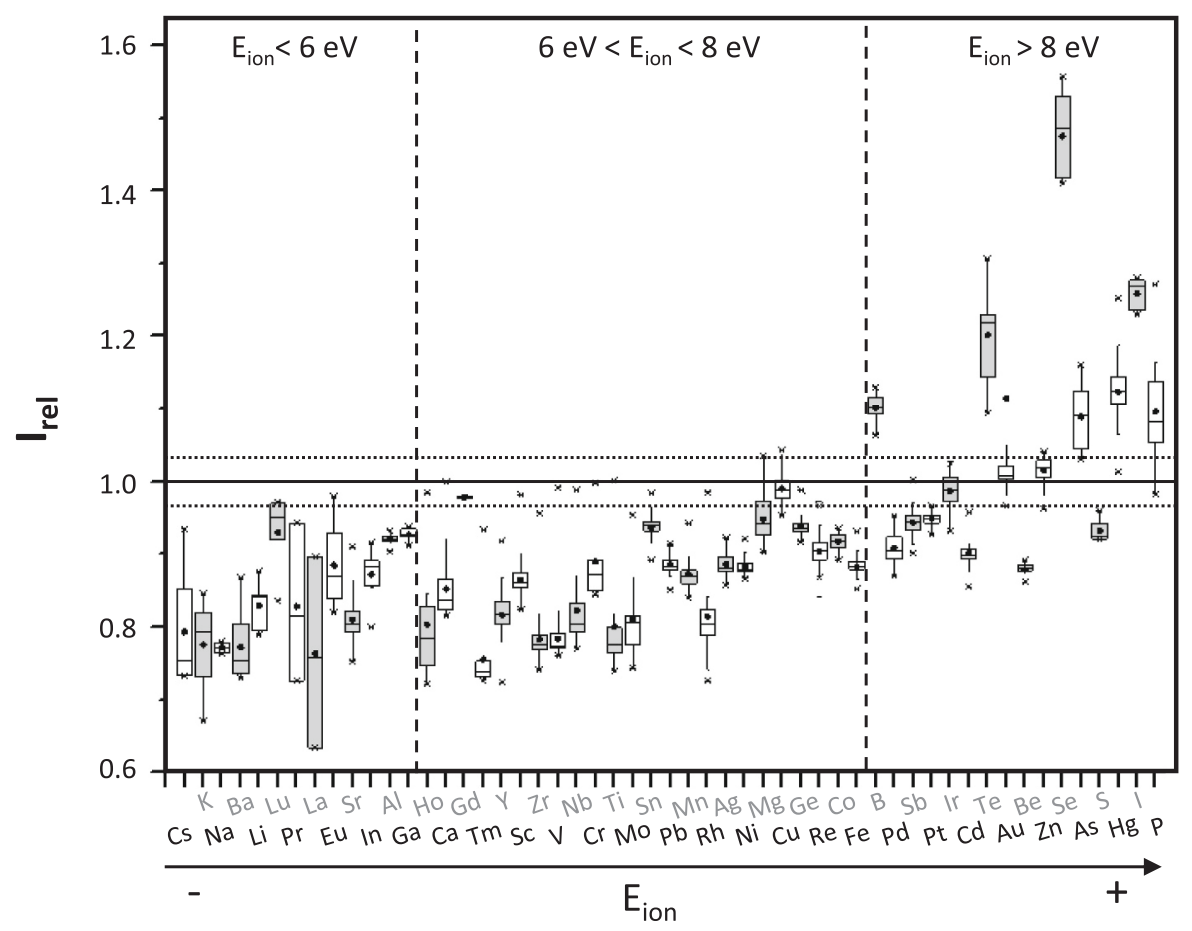

Fig. 3. Relative signal intensity ( $\left.\mathrm{I}_{\text {rel }}\right)$ obtained for a glycerol solution $\left(20 \mathrm{~g} \mathrm{~L}^{-1} \mathrm{C}\right.$ solution) in comparison to $1.0 \% \mathrm{w} \mathrm{w}^{-1}$ nitric acid for atomic lines according to analyte ionization energy $\left(E_{\text {ion }}\right)$. $I_{\text {rel }}$ values among horizontal dotted lines indicate no measurable matrix effects within the experimental uncertainties.

in the plasma.

\subsection{Origin of carbon matrix effects}

Matrix effects due to carbon in ICP-OES has been attributed to changes in: (i) aerosol generation, (ii) aerosol and analyte transport; (iii) plasma characteristics (e.g. electron temperature, etc.); and (iv) excitation/ionization mechanisms in the plasma [1,4,5,10-13]. As it has been previously pointed out, when operating $20 \mathrm{~g} \mathrm{~L}^{-1}$ carbon containing solutions made from glycerol, neither factors (i), (ii) nor (iii) are significantly modified regarding the $1.0 \% \mathrm{w} \mathrm{w}^{-1} \mathrm{HNO}_{3}$ solution [10]. Therefore, and attending to the results previously discussed, carbon matrix effects in atomic lines must be related to changes in analyte excitation and ionization mechanisms.

\subsubsection{Signal enhancement}

The origin of carbon matrix effects for As-like elements in ICP-OES has been previously investigated by our research group $[10,12]$ and others $[11,13]$. Under given ICP operating conditions, analyte ionic and atomic population for any element relies on the simultaneous occurrence of different mechanisms. Thus, for a given plasma excitation conditions, ionic population depends on electron-impact ionization as well as Ar-based CT and the collision with metastable argon atoms $[16,18,26]$. On the other hand, atomic levels are mostly populated by two different mechanisms, electronic impact and ion-electron recombination [16,27]. The former depends on the population of the atom ground level and mostly affects the low energy atomic levels, whereas the later relies on the ionic population affecting atomic levels of high energy. In the case of As, given its high $\mathrm{E}_{\text {ion }}$, the population of atomic levels is higher (black levels in Fig. 4.A) than that of the ionic ones (grey levels in Fig. 4.A). Hence, electronic impact excitation is the main mechanism controlling excited As atomic levels. In addition, considering Maxwell electronic distribution and the large energy gaps between As electronic levels, the overall efficiency to promote electrons through climbing the energy-level ladder (i.e., a bottom-up energy flow) is not expected to be high. When carbon is introduced into the plasma, analyte ionization is enhanced by carbon-based CT reactions thus favouring the ion-electron recombination pathway and the population of high energy atomic levels (i.e., top-down energy flow). This mechanism simultaneously explains: (i) the signal enhancement reported for As-like elements (i.e., As, Hg, I, P, Se and Te) in ICP-MS when operating carboncontaining matrices [8]; and (ii) the increase in the $\mathrm{I}_{\text {rel }}$ values observed for atomic lines in ICP-OES with $E_{\text {upper level (Fig. 2) [10-12] }}$ and, as regards $\mathrm{Hg}$, signal enhancement of the $\mathrm{Hg}$ II $194.227 \mathrm{~nm}$ line.

Carbon-based CT reactions in ICP-MS have been previously examined from a theoretical point of view by our research group considering both spin conservation (Wigner's rule) and reaction energy defect $(\Delta \mathrm{E})$ [8]. According to Wigner's rule [28], the total spin angular momentum of the reactants and products are vector sums of the individual particles spin numbers and, hence, CT successfully occurs when a common spin state is found between the reactants and products. For instance, CT between $\mathrm{C}^{+}$and As atoms is feasible due to the availability of a singlet close to $\mathrm{C}^{+}$ionization energy and the presence of a common spin state (1) between the reactants and products [8]:

$\mathrm{C}^{+}\left({ }^{2} \mathrm{P}\right)+\mathrm{As}\left({ }^{4} \mathrm{~S}\right) \rightarrow \mathrm{C}\left({ }^{3} \mathrm{P}\right)+\left(\mathrm{As}^{+}\right){ }^{*}\left({ }^{1} \mathrm{D}\right) \Delta \mathrm{E}=0.22 \mathrm{eV}$

$S_{i}=\left|S_{i}\right|=\left(s_{C^{+}}+s_{A s}\right),\left(s_{C^{+}}+s_{A s}-1\right) \ldots,\left|s_{C^{+}}-s_{A s}\right|=2 \& 1$

$S_{f}=\left|S_{f}\right|=\left(s_{C}+s_{A s^{+}}\right),\left(s_{C}+s_{A s^{+}}-1\right) \ldots,\left|s_{C}-s_{A s^{+}}\right|=1$

Reaction energy defect $(\Delta E)$ is defined as the difference between the ionization energy of the particle which transfers the charge $\left(\mathrm{C}^{+}\right)$and the sum of the ionization and excitation potentials of the product ion $\left(\left(\mathrm{M}^{+}\right)\right.$ *). For appreciable CT to occur, species affected by this type of reaction should have at least one ionic electronic level close to the ionic ground state of the particle transferring the charge $\left(\mathrm{C}^{+}{ }_{\text {energy }} \approx\left(\mathrm{M}^{+}\right) *\right.$ energy $)$. Based on previous works about Ar-based CT reactions in ICP-OES $[18,29,30]$, the feasibility of carbon-based CT was high when $1.00 \mathrm{eV}<\Delta \mathrm{E}<-0.50$ $\mathrm{eV}$ (where the negative sign indicates that the ionization energy of $\left(\mathrm{M}^{+}\right)$ * exceeds that of $\mathrm{C}^{+}$). According to these criteria, As, Hg, I, P, Se and Te fulfill CT reaction requirements with $\mathrm{C}^{+}$. In the case of $\mathrm{B}$, its high $\Delta \mathrm{E}$ (i. e., $-1.67 \mathrm{eV}$ ) does not explain a CT reaction with $\mathrm{C}^{+}$although a $\mathrm{CO}_{2}^{+}$based CT reaction would be feasible [8]. The significance of the latter 
A

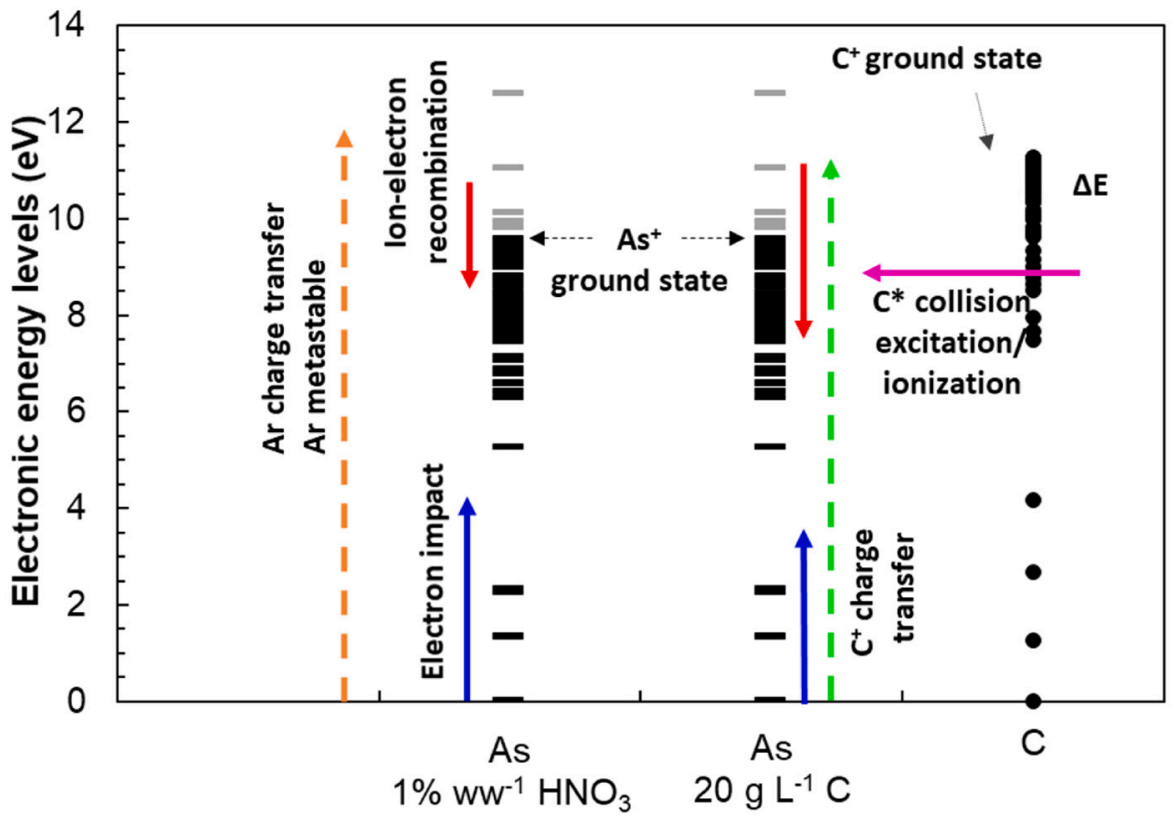

B

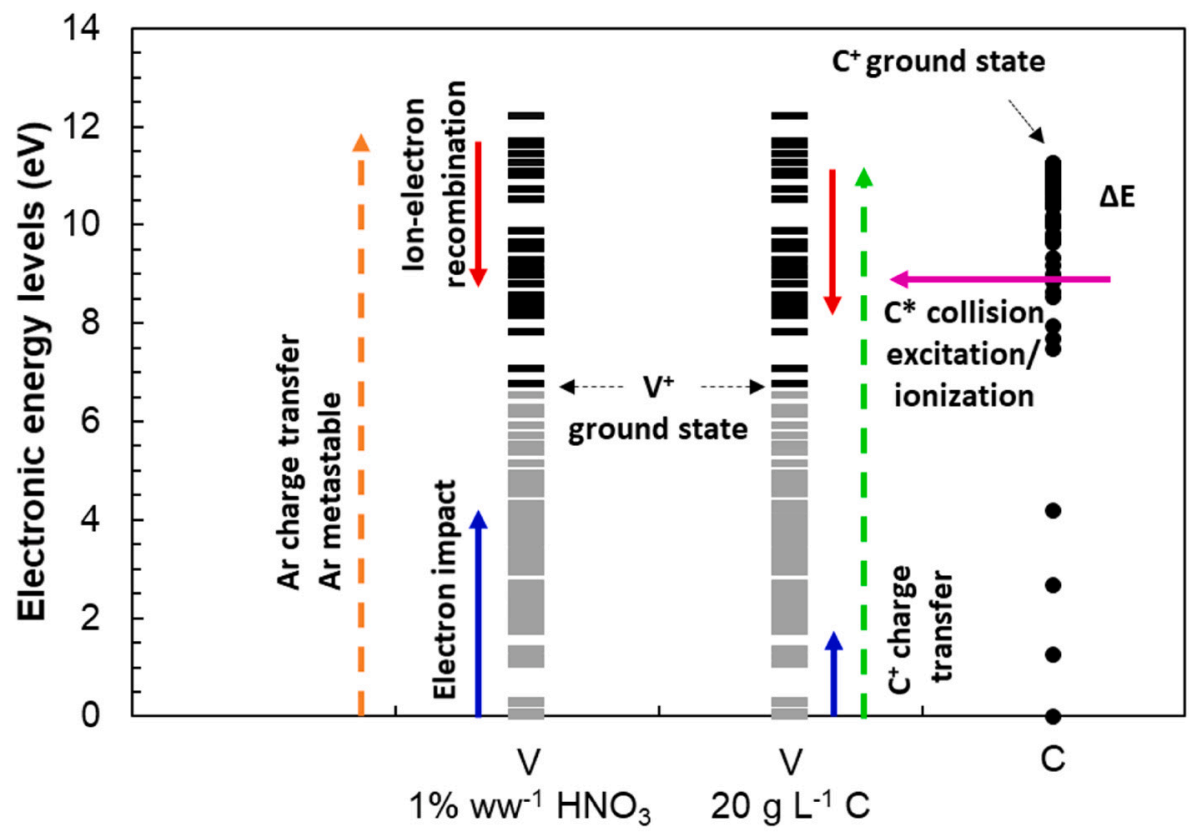

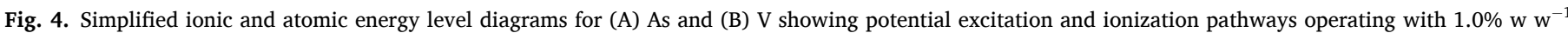
nitric acid and a glycerol solution $\left(20 \mathrm{~g} \mathrm{~L}^{-1} \mathrm{C}\right.$ solution). Electronic levels in black are expected to be more populated than those in grey.

mechanisms is, however, less likely considering that $\mathrm{CO}_{2}^{+}$levels in the plasma are 1000 -fold lower than those of $\mathrm{C}^{+}$[8]. Nevertheless, that previous study about carbon-based CT fundamentals in ICP-MS shows several shortcomings. First, the above-mentioned interpretation of the Wigner's rule predicts high CT probability even when there is a very large change in the electronic configuration (e.g., a three-electron transfer reaction). Several authors have pointed out that experimental data about CT reactions are better explained considering a strictest interpretation of the Wigner spin rules $[17,18,31]$. According to them, the total spin before and after the charge exchange should remained the same. This means that, since $\mathrm{C}^{+}$gains one spin-state during CT (from a doublet, ${ }^{2} \mathrm{P}$, to a triplet, ${ }^{3} \mathrm{P}$ ), the metal atom undergoing CT must upon ionization loses one spin-state.

$S_{i}=s_{C^{+}}+s_{M}=s_{C}+s_{\left(M^{+}\right)^{*}}=S_{f}$

$S_{i}=2+s=3+(s-1)=S_{f}$

Interestingly, other authors have proposed a different interpretation of this rule suggesting that the spin multiplicity of the analyte can increase or decrease by one spin multiplicity after CT. For instance, an 
atomic doublet can be transformed into either an ionic singlet or triplet after the CT $[18,32,33]$. Second, the $\Delta \mathrm{E}$ range assume for successful CT between $\mathrm{C}^{+}$and analyte atoms is probably too conservative. Experimental data in ICP-OES suggest that Ar-based CT reactions could even proceed with $\Delta \mathrm{E}$ larger than $\pm 1.00 \mathrm{eV}$ (e.g., Pt, Sn) $[16,18]$. Finally, it is usually considered that $\mathrm{CT}$ involves the ground state of the charge acceptor atom (M) but experimental evidences suggest that this process might be also feasible from low-lying atomic levels $\left(\mathrm{M}^{*}\right)$ when their population density is significant [16]. Therefore, the feasibility of carbon-based CT reactions for As, Hg, I, P, Se and Te have been reexamined considering: (i) the different interpretations of Wigner spin rule (i.e., strictest version: analyte undergo a spin change of -1 ; intermediate version: analyte undergo a spin change of \pm 1 ); (ii) a larger $\Delta \mathrm{E}$ range $(-1.25 \mathrm{eV}<\Delta \mathrm{E}<1.25 \mathrm{eV})$. Charge transfer reactions within this range are expected to proceed faster than those outside this range; and (iii) the involvement of both ground and low-lying electronic levels of analyte atoms. For low-lying electronic levels, because the lower abundance of the species involved, CT reaction rate should proceed slower than those involving ground electronic levels. Table 2 shows the spectroscopic data for the most likely analyte electronic levels of As, B, Hg, I, P, Se and Te involved in $\mathrm{CT}$ reactions with $\mathrm{C}^{+}$. For electronic levels of high population density fulfilling reaction requirements, CT feasibility is classified as high. Conversely, CT feasibility is low when: (i) the population density of a given electronic state is limited (i.e., Boltzmann-Maxwell distribution); (ii) the Wigner's rule in its most strictest or intermediate interpretation are not fulfilled; or (iii) $\Delta \mathrm{E}$ is not within $-1.25 \mathrm{eV}<\Delta \mathrm{E}<$ $1.25 \mathrm{eV}$.

As it is shown in Table 2, the closest ionic electronic level to the $\mathrm{C}^{+}$ ground state (i.e., $11.26 \mathrm{eV})$ for $\operatorname{Se}\left({ }^{2} \mathrm{D}_{3 / 2,5 / 2} ; \mathrm{E}=11.38 / 11.55 \mathrm{eV}\right)$ and Te $\left({ }^{2} \mathrm{P}_{1 / 2,3 / 2} ; \mathrm{E}=11.55 / 11.98 \mathrm{eV}\right)$ fulfills $\mathrm{CT}$ reaction requirements and, hence, they are likely to participate in such reactions. This conclusion agrees with that obtained in our previous study about carbon-based CT requirements [8]. Interestingly, when using the strictest version of Wigner spin conservation rule, it is observed that total spin is not preserved for those ionic electronic levels of $A s\left({ }^{1} D_{2}\right)$ and $P\left({ }^{1} D_{2}\right)$ previously proposed to react with $\mathrm{C}^{+}[8]$. Thus, for instance, when considering the As ground state term $\left({ }^{4} \mathrm{~S}_{3 / 2}\right)$, CT would successfully proceed if the $\mathrm{As}^{+}$ state is a triplet. However, the closet ionic level to $\mathrm{C}^{+}$ground state is a singlet $\left({ }^{1} \mathrm{D}_{2}\right.$ at $\left.11.04 \mathrm{eV}\right)$. In fact, this specific reaction requires from spin flipping.

$S_{i}=s_{C^{+}}+s_{A s}=2+4=6$

$S_{f}=s_{C}+s_{\left(A s^{+}\right)^{*}}=3+1=4$

Though there are literature examples showing that spin-forbidden reactions are feasible, they proceed with a slower rate than those spinallowed, and, hence, carbon matrix effects are not expected to be related to electronic levels involved in such reactions $[17,18]$. Therefore, the feasibility of CT reactions for other electronic levels for the above-mentioned elements was checked. Because the presence of lowlying atomic levels for As $\left({ }^{2} \mathrm{D}_{3 / 2,5 / 2} ; \mathrm{E}=1.31 / 1.35 \mathrm{eV}\right)$, CT could successfully proceed with a singlet ionic state $\left({ }^{1} \mathrm{~S}_{0}\right)$ at $12.59 \mathrm{eV}$. From the Boltzmann-Maxwell distribution, and considering an average plasma temperature of $7600 \mathrm{~K}$ (See Section 3.3.1, Table 6), the population density of the low-lying atomic level of As is significant (i.e., approximately one third of that of the ground state). An alternative pathway could involve $\mathrm{As}^{+}$triplet $\left({ }^{3} \mathrm{P}_{0,1,2} ; \mathrm{E}=9.79-10.10 \mathrm{eV}\right)$ since $\mathrm{CT}$ reaction requirements are also fulfilled assuming the strictest interpretation of Wigner's spin rule. Following the same reasoning for $\mathrm{P}$, the most likely candidate is $\mathrm{P}^{+}$triplet $\left({ }^{3} \mathrm{P}_{0,1,2} ; \mathrm{E}=10.48 / 10.53 \mathrm{eV}\right)$. Finally, as regards $\mathrm{Hg}$ and $\mathrm{I}$, a close inspection of spectroscopic data suggest that carbonbased CT could only occur assuming the intermediate interpretation of Wigner's spin rule with a $\mathrm{Hg}^{+}$doublet $\left({ }^{2} \mathrm{~S}_{1 / 2} ; \mathrm{E}=10.44 \mathrm{eV}\right)$ and $\mathrm{I}^{+}$ singlet $\left({ }^{3} \mathrm{P}_{2,1,0} ; \mathrm{E}=10.45 / 11.33 \mathrm{eV}\right)$. Signal enhancement observed for the Hg II $194.227 \mathrm{~nm}$ emission wavelengths partially supports this mechanism $\left(\left({ }^{2} \mathrm{P}_{1 / 2}(16.82 \mathrm{eV}) \rightarrow{ }^{2} \mathrm{~S}_{1 / 2}(10.44 \mathrm{eV})\right)\right.$. Nevertheless, in the case of I, CT reactions could also proceed with a different electronic level $\left({ }^{1} \mathrm{D}_{2} ; \mathrm{E}=12.15 \mathrm{eV}\right)$ assuming the strictest interpretation of Wigner's spin rule.

Special mention deserves the behavior of B. Charge transfer probability between $\mathrm{B}$ ground state and $\mathrm{C}^{+}$is expected to be low due to the absence of an appropriate electronic level (Table 2). Nakazawa et al. [15] have shown that, under conventional plasma conditions, $\mathrm{BO}^{+}$ population in the plasma is significant $(\approx 4 \%)$ due to the high energy of boron oxide bond $\left(809 \mathrm{~kJ} \mathrm{~mol}^{-1}\right)$. It is expected that, because of carbon introduction into the plasma, boron oxide levels would be reduced due to the higher affinity of carbon to oxygen $\left(1076 \mathrm{~kJ} \mathrm{~mol}^{-1}\right)$, thus increasing $\mathrm{B}$ atomic population and atomic emission [15]:

$\mathrm{BO}+\mathrm{C} \rightarrow \mathrm{CO}+\mathrm{B}$ Oxide reduction

Nevertheless, if signal enhancement would be related to this mechanism, the emission signal for atomic lines of other elements showing high oxygen bond strengths (e.g. La, $799 \mathrm{~kJ} \mathrm{~mol}^{-1}$; $\mathrm{Zr}, 776 \mathrm{~kJ} \mathrm{~mol}^{-1}$ ) should have also been enhanced in the presence of carbon but no experimental evidences were noticed (Table S2, Appendix). From the above-mentioned discussion and given the experimental data obtained in this work, it is not feasible to determine unambiguously the origin of matrix effects for B atomic lines.

A close inspection of carbon atomic levels (Fig. 4.A) suggest that an additional mechanism based on carbon species could also play a significant role on matrix effects for As-like elements. Most of the electronic states for $\mathrm{C}$ atoms lies between 7.48 and $11.26 \mathrm{eV}$ and, hence, they have enough energy to ionize and excite As-like elements.

$$
\begin{aligned}
& C^{*}+\mathrm{M} \rightarrow \mathrm{C}+M^{+}+e^{-} \text {Collisional ionization } \\
& C^{*}+\mathrm{M} \rightarrow \mathrm{C}+M^{*} \quad \text { Collisional excitation }
\end{aligned}
$$

Table 2

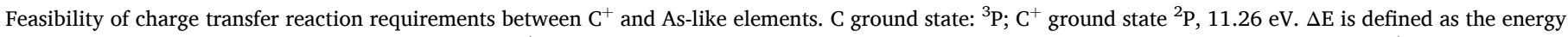

\begin{tabular}{|c|c|c|c|c|c|c|c|}
\hline \multirow[t]{2}{*}{ Analyte } & \multicolumn{2}{|c|}{ Atom electronic level } & \multicolumn{2}{|c|}{ Ion electronic level } & \multirow[t]{2}{*}{$\Delta \mathrm{E}(\mathrm{eV})$} & \multirow[t]{2}{*}{ Spin conservation } & \multirow[t]{2}{*}{ CT probability } \\
\hline & Term & Energy (eV) & Term & Energy (eV) & & & \\
\hline \multirow[t]{3}{*}{ As } & ${ }^{4} S_{3 / 2}$ & 0.00 & ${ }^{1} \mathrm{D}_{2}$ & 11.04 & 0.22 & No & Low \\
\hline & ${ }^{4} S_{3 / 2}$ & 0.00 & ${ }^{3} \mathrm{P}_{0,1,2}$ & $9.79 / 10.10$ & $1.16 / 1.47$ & Yes & High \\
\hline & ${ }^{2} D_{3 / 2,5 / 2}$ & $1.31 / 1.35$ & ${ }^{1} \mathrm{~S}_{0}$ & 12.59 & $-0.02 / 0.02$ & Yes & High \\
\hline \multirow[t]{2}{*}{ B } & ${ }^{2} \mathrm{P}_{1 / 2,3 / 2}$ & 0.00 & ${ }^{3} \mathrm{P}_{0,1,2}$ & 12.93 & -1.67 & Yes* & Low \\
\hline & ${ }^{2} \mathrm{P}_{1 / 2,3 / 2}$ & 0.00 & ${ }^{1} \mathrm{~S}_{0}$ & 8.30 & 2.96 & Yes & Low \\
\hline $\mathrm{Hg}$ & ${ }^{1} \mathrm{~S}_{0}$ & 0.00 & ${ }^{2} S_{1 / 2}$ & 10.44 & 0.82 & Yes* & High \\
\hline \multirow[t]{2}{*}{ I } & ${ }^{2} \mathrm{P}_{3 / 2,1 / 2}$ & $0.00 / 0.94$ & ${ }^{3} \mathrm{P}_{2,0,1}$ & $10.45 / 11.33$ & $-0.07 / 1.75$ & Yes* & High \\
\hline & ${ }^{2} \mathrm{P}_{3 / 2,1 / 2}$ & $0.00 / 0.94$ & ${ }^{1} \mathrm{D}_{2}$ & 12.15 & $-0.89 / 0.05$ & Yes & High \\
\hline \multirow[t]{2}{*}{$\mathrm{P}$} & ${ }^{4} S_{3 / 2}$ & 0.00 & ${ }^{1} \mathrm{D}_{2}$ & 11.60 & -0.34 & No & Low \\
\hline & ${ }^{4} S_{3 / 2}$ & 0.00 & ${ }^{3} \mathrm{P}_{0,1,2}$ & $10.48 / 10.53$ & $0.73 / 0.78$ & Yes & High \\
\hline $\mathrm{Se}$ & ${ }^{3} \mathrm{P}_{2,1,0}$ & $0.00 / 0.31$ & ${ }^{2} \mathrm{D}_{3 / 2,5 / 2}$ & $11.38 / 11.45$ & $-0.19 / 0.19$ & Yes & High \\
\hline $\mathrm{Te}$ & ${ }^{3} \mathrm{P}_{2,0,1}$ & $0.00 / 0.59$ & ${ }^{2} \mathrm{P}_{1 / 2,3 / 2}$ & $11.55 / 11.98$ & $-0.72 / 0.30$ & Yes & High \\
\hline
\end{tabular}
defect between the particle that transfer the charge $\left(\mathrm{C}^{+}\right)$and the sum of the ionization and excitation potentials of the analyte ion generated $\left(\left(\mathrm{M}^{+}\right)^{*}\right)$.

* Intermediate interpretation of Wigner's spin rule. 
According to this scheme, the high energy atomic levels might be populated by two different pathways: (i) analyte ionization (Penninglike ionization) followed by an ion-electron recombination process; and/ or, (ii) directly by collision with carbon excited species. Unlike carbonbased CT reactions, energetic differences between analyte atomic levels and excited carbon species are less critical since any energy mismatch between both species could be accommodated by means of the kinetic energy of the particles involved [26]. Because collisional ionization is also dependent on plasma electron density, it is compatible with previous experiments by our research group in which carbon-based matrix effects on atomic emission for As-like elements decreased in the presence of easily ionizable elements (i.e., $\mathrm{K}$ and $\mathrm{Ca}$ ) [12]. Nevertheless, according to this scheme, other hard-to-ionize elements (e.g. Au, Zn, etc.) should behave similarly but no experimental evidences of signal enhancement on the emission of atomic lines have been found. Unfortunately, to gain insight into the occurrence of all the mentioned mechanisms, a detailed study of the population of all the species involved in these mechanisms (e.g. $\mathrm{C}^{*}, \mathrm{C}^{+}, \mathrm{C}, \mathrm{M}, \mathrm{M}^{*}, \mathrm{M}^{+}$, etc.) would be needed but such study requires a complex setup based on lasers that cannot be employed with commercial ICP-OES instruments [17].

\subsubsection{Signal suppression}

Signal suppression induced by carbon on atomic emission has been previously attributed to the formation of stable carbide compounds as well as to collisional deactivation of the excited analyte states but experimental evidences supporting them are scarce and limited to a very few elements and lines [10,11,19]:

\section{$\mathrm{C}+\mathrm{M} \rightarrow \mathrm{CM}$ Carbide formation}

$\mathrm{C}+M^{*} \rightarrow C^{*}+\mathrm{M}$ Collisional deactivation

In the present work, the potential influence of the above-mentioned mechanisms on the atomic emission signal has been systematically investigated. First, it has been checked whether carbide formation is responsible of signal suppression for atomic lines. To this end, data about C-element bond formation energy available in the literature [34] was collected and compare to experimental $I_{\text {rel }}$ values (Table 3). For each element, the wavelength showing the strongest signal suppression (i.e., lowest $\mathrm{I}_{\text {rel }}$ values) was selected. Results showed that there were no correlation between carbide bond strength energy and signal suppression. For instance, despite the carbide bond energy for $\mathrm{S}\left(714 \mathrm{~kJ} \mathrm{~mol}^{-1}\right)$ is 2.8-fold higher than that for $\mathrm{Al}\left(255 \mathrm{~kJ} \mathrm{~mol}^{-1}\right)$, no differences in matrix effects are observed between both species (S: $\mathrm{I}_{\text {rel }} 0.92 \pm 0.02 ; \mathrm{Al}$ : $\left.\mathrm{I}_{\text {rel }} 0.90 \pm 0.01\right)$. Similarly, the carbide bond energy for $\mathrm{Zr}(561 \mathrm{~kJ}$ $\mathrm{mol}^{-1}$ ) was lower than that for $\mathrm{S}$ but signal suppression was more

\section{Table 3}

Relative signal intensity ( $\mathrm{I}_{\text {rel }}$ ) obtained for a $20 \mathrm{~g} \mathrm{~L}^{-1}$ carbon-containing solution (glycerol) in comparison to $1.0 \% \mathrm{w} \mathrm{w}^{-1}$ nitric acid for atomic lines and the corresponding carbon-analyte bond energy. Wavelengths included corresponds to those atomic lines showing the lowest $\mathrm{I}_{\mathrm{rel}}$ values. Uncertainties for $\mathrm{I}_{\mathrm{rel}}$ values are presented as the standard deviation of 3 replicates.

\begin{tabular}{lllll}
\hline Element & Wavelength $(\mathrm{nm})$ & $\mathrm{E}_{\text {upper level }}(\mathrm{eV})$ & $\mathrm{I}_{\text {rel }}$ & $\mathrm{M}-\mathrm{C}\left(\mathrm{kJ} \mathrm{mol}^{-1}\right)$ \\
\hline $\mathrm{Al}$ & 394.401 & 3.143 & $0.90 \pm 0.01$ & 255 \\
$\mathrm{Ni}$ & 346.165 & 3.606 & $0.88 \pm 0.01$ & 337 \\
$\mathrm{Fe}$ & 385.991 & 3.211 & $0.85 \pm 0.01$ & 376 \\
$\mathrm{Y}$ & 668.757 & 1.853 & $0.72 \pm 0.01$ & 418 \\
$\mathrm{Ti}$ & 521.039 & 2.427 & $0.74 \pm 0.01$ & 423 \\
$\mathrm{~V}$ & 486.473 & 2.565 & $0.76 \pm 0.01$ & 427 \\
$\mathrm{Pd}$ & 379.919 & 4.224 & $0.87 \pm 0.01$ & 436 \\
$\mathrm{Sc}$ & 404.779 & 3.083 & $0.83 \pm 0.01$ & 444 \\
$\mathrm{Ge}$ & 323.949 & 4.674 & $0.93 \pm 0.01$ & 460 \\
$\mathrm{La}$ & 510.624 & 2.758 & $0.63 \pm 0.01$ & 462 \\
$\mathrm{Mo}$ & 390.295 & 3.176 & $0.76 \pm 0.01$ & 481 \\
$\mathrm{Zr}$ & 612.748 & 2.177 & $0.74 \pm 0.01$ & 561 \\
$\mathrm{Nb}$ & 509.529 & 2.519 & $0.77 \pm 0.04$ & 569 \\
$\mathrm{Rh}$ & 369.236 & 3.357 & $0.73 \pm 0.01$ & 580 \\
$\mathrm{Pt}$ & 340.813 & 3.739 & $0.95 \pm 0.01$ & 598 \\
$\mathrm{~S}$ & 181.972 & 6.860 & $0.92 \pm 0.01$ & 714 \\
\hline
\end{tabular}

significant for the former element $\left(\mathrm{I}_{\mathrm{rel}} 0.74 \pm 0.02\right)$. As regards collisional deactivation hypothesis, this mechanism would be likely for those excited species that possess an excited atomic-state energy close to that of carbon atoms (e.g. ${ }^{1} \mathrm{D} 1.26 \mathrm{eV} ;{ }^{1} \mathrm{~S} 2.68 \mathrm{eV},{ }^{5} \mathrm{~S} 4.18 \mathrm{eV},{ }^{3} \mathrm{P} 7.48 \mathrm{eV},{ }^{3} \mathrm{D}$ $8.65 \mathrm{eV}$, etc.) and, for this reason, higher matrix effects (i.e., signal suppression) should be expected for them [20]. A close inspection of experimental data reveals that there was not any specific trend in $\mathrm{I}_{\text {rel }}$ values for those analytes with excited atomic states near to the carbon ones. Therefore, it can be derived that the origin of the carbon-induced signal emission suppression cannot be attributed to neither carbide formation nor collisional deactivation mechanisms. In fact, if the above mechanisms would be correct, similar reactions are expected for the ionic population of the analyte. As a result, analyte ionic population would also have been affected and, hence, the emission signal of ionic lines. However, emission signal for ionic lines was unaffected in the presence of carbon matrix (Table S1, Appendix).

Since both carbon-based CT reactions and collision with excited atomic carbon seem to be the main responsible of the matrix effects observed for As-like elements, we have investigated whether these mechanisms were also responsible of signal suppression. The hypothesis is based on the observation that the atomic lines showing signal suppression correspond to analytes that were almost completely ionized in the plasma (e.g. 99\% for V) (black levels in Fig. 4.B) and, hence, the above-mentioned mechanisms would have a great impact on the (limited) analyte atomic population present in the plasma (grey levels in Fig. 4.B). For this kind of elements, because the high ionic population and the small energy gaps between atomic levels, changes on the overall mechanisms populating atomic levels of high energy (i.e., bottom-up vs top-down energy flow) by carbon is marginal with regard As-like elements. However, this is not true for low energy electronic levels since carbon-based CT transfer affects (the limited) analyte ground state population and, hence, the population of (low energy) excited states. These carbon-based mechanisms would simultaneously explain the lack of matrix effects on the emission of ionic lines (i.e., ionic populations remain mostly unaltered) and matrix effects dependence on atomic lines with $\mathrm{E}_{\text {upper level. }}$

To evaluate the potential occurrence of the aforementioned carbonbased mechanisms, carbon matrix effects were investigated under the presence of easily ionizable elements since these species affects discharge electron density and ion-atom equilibrium [12]. To this end and given the high number of ionic and atomic lines available in ICPOES, V was selected as model analyte. A $200 \mathrm{mg} \mathrm{L}^{-1} \mathrm{~V}$ reference solution $\left(1 \% \mathrm{w} \mathrm{w}^{-1} \mathrm{HNO}_{3}\right)$ and the $\mathrm{C}$-containing solution $\left(20 \mathrm{~g} \mathrm{~L}^{-1} \mathrm{C}\right)$ were spiked with different amounts of calcium (2000 and 20,000 $\mathrm{mg} \mathrm{L}^{-1}$ ). For each carbon solution, $\mathrm{I}_{\text {rel }}$ for $\mathrm{V}$ atomic lines was calculated relative to $1 \%$ $\mathrm{w} \mathrm{w}{ }^{-1} \mathrm{HNO}_{3}$ solution containing the same amount of calcium. As expected from previous works in the literature, and irrespective of the matrix considered $\left(20 \mathrm{~g} \mathrm{~L}^{-1} \mathrm{C}\right.$ or $\left.1.0 \mathrm{w} \mathrm{w}^{-1} \mathrm{HNO}_{3}\right)$, it was observed that both atomic and ionic emission signal decreased with Ca concentration $[26,35,36]$. Fig. 5 shows the $\mathrm{I}_{\text {rel }}$ values obtained for $\mathrm{V}$ atomic and ionic lines operating a $20 \mathrm{~g} \mathrm{~L}^{-1}$ carbon solution for different Ca levels. In agreement with previous experiments for non-Ca containing solutions, no measurable matrix effects within experimental uncertainties were registered for $\mathrm{V}$ ionic lines operating the carbon matrix with regard the reference solution. However, $\mathrm{I}_{\text {rel }}$ values for $\mathrm{V}$ atomic lines increased in the presence of $\mathrm{Ca}$. Interestingly, the increase in $\mathrm{I}_{\text {rel }}$ was more significant

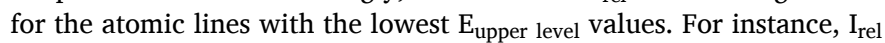
values for $\mathrm{V}$ emission lines with $\mathrm{E}_{\text {upper level }}$ values about $2.5 \mathrm{eV}$ increased from $0.79 \pm 0.02$ to $0.95 \pm 0.02$ (i.e., $20 \%$ ), whereas $\mathrm{I}_{\text {rel }}$ raise for

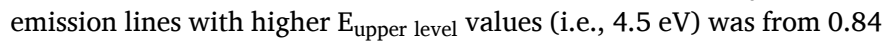
\pm 0.02 to $0.95 \pm 0.02$ (i.e., $13 \%$ ). According to these data, the observed net matrix effects diminished in the presence of $\mathrm{Ca}$. This behavior is easily explained by considering that the higher electronic density afforded by Ca: (i) increases analyte atomic population; (ii) reduces carbon-charged species population; and (iii) favours electron collision with regard ion-electron recombination [10,12]. Matrix effects 


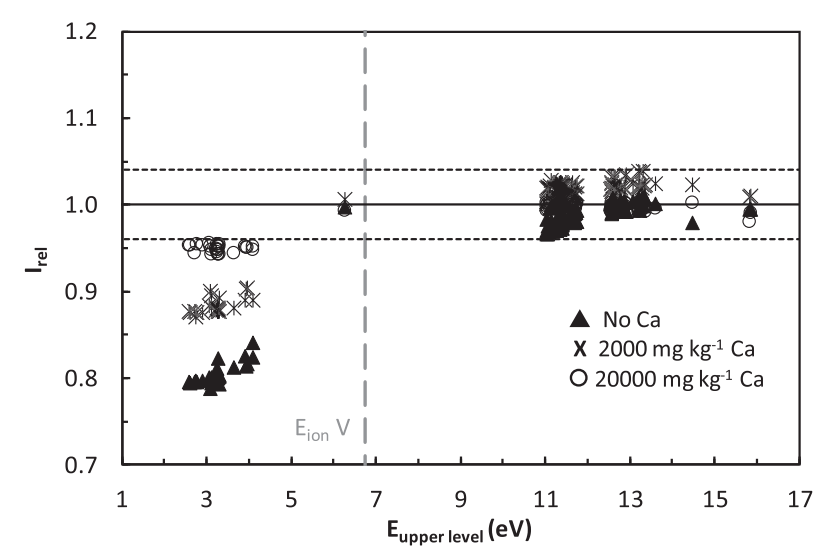

Fig. 5. Relative signal intensity $\left(\mathrm{I}_{\mathrm{rel}}\right)$ obtained for $\mathrm{V}$ atomic and ionic emission lines operating a glycerol solution $\left(20 \mathrm{~g} \mathrm{~L}^{-1} \mathrm{C}\right.$ solution) with different amounts of calcium in comparison with the equivalent solution in $1.0 \% \mathrm{w} \mathrm{w}^{-1}$ nitric acid. $I_{\text {rel }}$ values among horizontal dotted lines indicate no measurable matrix effects within the experimental uncertainties.

reduction for V-like elements operating carbon/calcium-matrices was analogous to those previously registered for As-like ones [12] thus suggesting that both carbon-based CT reactions and collision with excited atomic carbon play indeed a simultaneous role on both signal enhancement and signal suppression of atomic emission.

From a theoretical point of view (Table 4), carbon-based CT reaction might be expected for $\mathrm{Ag}, \mathrm{Al}, \mathrm{Ba}, \mathrm{Ca}, \mathrm{Co}, \mathrm{Cr}, \mathrm{Eu}, \mathrm{Fe}, \mathrm{Ga}$, In, La, Lu, Mg, Mn, Mo, Nb, Ni, Pd, Pt, Re, Rh, S, Sb, Sc, Sr, Ti, V, Y and Zr. For these elements, potential electronic states are significantly populated and fulfill spin conservation (either strictest or intermediate interpretation) and $\Delta \mathrm{E}$ requirements. However, $\mathrm{CT}$ probability for $\mathrm{Be}, \mathrm{Cd}, \mathrm{Cs}, \mathrm{Ge}, \mathrm{K}, \mathrm{Li}$, $\mathrm{Na}, \mathrm{Pb}$ and $\mathrm{Sn}$ is expected to be low due to the most likely states do not fulfill all the CT requirements, particularly $\Delta \mathrm{E}$. For instance, among alkali elements, $\Delta \mathrm{E}$ for $\mathrm{Li}, \mathrm{Na}$ and $\mathrm{K}$ is $5.87,6.12$ and $6.92 \mathrm{eV}$, respectively. No conclusion was feasible for Pr, Ho and Tm due to the limited spectroscopic information available for these species [20-23]. As regards the collisional mechanisms based on excited atomic carbon, all the elements might be theoretically involved due to requirements are less demanding than with $\mathrm{CT}$ reactions (i.e., $\Delta \mathrm{E}$ and spin conservation) and they show several (ionic and atomic) electronic levels with energies matching those of carbon atoms. Nevertheless, it is important to remark that, for some elements (Ag, Al, Be, Cd, Cs, Ga, Ge, In, K, Li, Mg, Na, Pb, $\mathrm{Pd}, \mathrm{Pt}, \mathrm{S}, \mathrm{Sb}, \mathrm{Sn}$ and $\mathrm{Sr}$ ), the number of ionic levels is rather limited between 7.48 and $11.26 \mathrm{eV}(<3$ levels) and, therefore, the pathway based on excited atomic carbon is expected to be more significant.

\subsubsection{No measurable matrix effects within experimental uncertainties}

The lack of matrix effects on the atomic emission signal for Zn-like elements (i.e., $\mathrm{Au}, \mathrm{Cu}, \mathrm{Gd}$, Ir and $\mathrm{Zn}$ ) was striking considering the previous findings for As and V-like elements. In fact, the lack of matrix effects shown by $\mathrm{Au}$ atomic lines was remarkable since several works have previously shown that Au ionization in ICP-MS is enhanced by carbon-based CT reactions [8,14]. Just as V-like elements, the potential occurrence of carbon-based CT reaction was examined (Table 5). With the exception of $\mathrm{Zn}$, all the elements in this group (i.e., $\mathrm{Au}, \mathrm{Cu}, \mathrm{Gd}$ and $\mathrm{Ir}$ ) have an electronic state fulfilling carbon-based CT reaction requirements (either assuming the strictest or the intermediate version of Wigner's spin rule) so, a priori, atomic emission should have shown a similar behavior to As- and V-like elements. As regards Zn, the lack of matrix effects on atomic emission could be explain by the high $\Delta \mathrm{E}$ for those electronic levels potentially involved in $\mathrm{CT}$ reactions with $\mathrm{C}^{+}$. On the other hand, all the above-mentioned elements have both ionic and atomic levels close to those of carbon and, hence, they could be involved in collisional (excitation/ionization) processes with atomic carbon.
Further insight on the lack of matrix effects for these elements requires to measure the population of the different analyte and carbon species present in the discharge. Unfortunately, as it has been previously mentioned, it is not feasible with commercial instruments.

\subsection{Practical considerations derived from carbon matrix effects in ICP- OES}

Because carbon matrix effects exert a strong influence on the emission signal for atomic lines in ICP-OES, it is expected that elemental analysis for carbon-rich matrices are biased. Therefore, it has been examined how to detect and mitigate carbon matrix effects in ICP-OES.

\subsubsection{Plasma characterization}

To evaluate the existence and magnitude of non-spectral interferences in ICP-OES, different plasma parameters could be monitored such as plasma electron and excitation temperatures $\left(\mathrm{T}_{\text {exc }}\right)$ [37]. Though several plasma parameters could be directly measured using the emission of Ar atomic lines or plasma background (e.g., electronic temperature and electron density) [24,38], some strategies rely on the use of the ionic and/or atomic emission of a given element introduced into the plasma as analytical probe. Thus, for instance, $\mathrm{T}_{\text {exc }}$ may be estimated by means the Boltzmann plot using Fe atomic lines [37,39] or by means the line pair intensity ratio using Ti II lines (e.g. Ti II $322.284 \mathrm{~nm} / \mathrm{Ti}$ II $322.424 \mathrm{~nm}$ ) [37]. Because carbon matrix effects, biased results in plasma parameters might be obtained operating the emission of atomic lines when compared to the ionic ones. In fact, contradictory results have already been reported about carbon influence on plasma characteristics regarding acidic solutions $[10,12]$. Therefore, given the new findings presented in this work about carbon matrix effects, several plasma characterization methodologies based on analyte (ionic and atomic) emission were reexamined to determine their strengths and weakness when operating carbon rich matrices. To evaluate both wavelength and analyte characteristics on plasma excitation temperature estimates afforded by the Boltzmann plot, ionic and atomic lines of $\mathrm{Fe}$ and $\mathrm{Ti}$ were employed. Wavelengths and transition probability values for $\mathrm{Fe}$ and $\mathrm{Ti}$ emission lines were obtained from different database $[23,40,41]$. In addition, due to its wider use for assessing plasma robustness, the $\mathrm{Mg}$ II $280.270 \mathrm{~nm} / \mathrm{Mg}$ I $285.213 \mathrm{~nm}$ ratio was also employed $[37,42]$. Because differences in instrument response, the $\mathrm{Mg}$ II $280.270 \mathrm{~nm} / \mathrm{Mg}$ I $285.213 \mathrm{~nm}$ ratio was corrected using the nearby background emission [37,42,43].

The results obtained using the above-mentioned methodologies operating both the $20 \mathrm{~g} \mathrm{~L}^{-1}$ carbon and the reference matrix solution are summarized in Table 6 . As it can be derived from data in Table 6 , the $\mathrm{T}_{\mathrm{exc}}$ afforded by the different methodologies was similar (average $\mathrm{T}_{\text {exc }} 7600$ $\mathrm{K})$. Interestingly, irrespective of the probe employed, no differences on $\mathrm{T}_{\text {exc }}$ were observed between the glycerol and the reference solution. Similar findings were obtained using the line pair intensity ratio for atomic and ionic emission lines of Fe and Ti (data not shown) [37]. The lack of change on $\mathrm{T}_{\text {exc }}$ when using ionic lines was not surprising considering that carbon does not affect ionic emission intensity. For atomic lines, however, it should be considered that excitation temperature is deduced from the plot of:

$\operatorname{Ln} \frac{I \lambda}{g A}$ vs $E_{\text {exc }}$

where $\lambda$ is analyte wavelength, I wavelength intensity, $g$ is the statistical weight $(g=2 \mathrm{~J}+1$, $\mathrm{J}$ being the total electronic angular momentum quantum number), $A$ is electronic transition probability factor and $E_{\text {exc }}$ is excitation energy. Because differences on atomic emission were not so large ( $<20 \%$ for Fe and Ti), and the damping effect of the Ln term, no changes on plasma temperature were observed within experimental uncertainties. From these results, it is obvious that $\mathrm{T}_{\text {exc }}$ obtained by means the Boltzmann plot using the emission of atomic lines was not 
Table 4

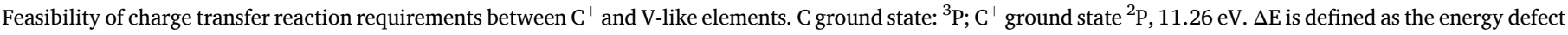
between the particle that transfer the charge $\left(\mathrm{C}^{+}\right)$and the sum of the ionization and excitation potentials of the analyte ion generated $\left(\left(\mathrm{M}^{+}\right) *\right)$.

\begin{tabular}{|c|c|c|c|c|c|c|c|}
\hline \multirow[t]{2}{*}{ Analyte } & \multicolumn{2}{|c|}{ Atom electronic state } & \multicolumn{2}{|c|}{ Ion electronic level } & \multirow[t]{2}{*}{$\Delta \mathrm{E}(\mathrm{eV})$} & \multirow[t]{2}{*}{ Spin conservation } & \multirow[t]{2}{*}{ CT probability } \\
\hline & Term & Energy (eV) & Term & Energy (eV) & & & \\
\hline \multirow[t]{2}{*}{$\mathrm{Ag}$} & ${ }^{2} \mathrm{~S}_{1 / 2}$ & 0.00 & ${ }^{1} \mathrm{~S}_{0}$ & 7.57 & 3.69 & Yes & Low \\
\hline & ${ }^{2} \mathrm{~S}_{1 / 2}$ & 0.00 & ${ }^{2}[5 / 2]_{3,2}$ & $12.43 / 12.62$ & $-1.17 /-1.36$ & Yes & High \\
\hline \multirow[t]{2}{*}{$\mathrm{Al}$} & ${ }^{2} \mathrm{P}_{1 / 2,3 / 2}$ & $0.00 / 0.01$ & ${ }^{1} \mathrm{~S}_{0}$ & 5.98 & $5.28 / 5.29$ & Yes & Low \\
\hline & ${ }^{2} \mathrm{P}_{1 / 2,3 / 2}$ & $0.00 / 0.01$ & ${ }^{3} \mathrm{P}_{0,1,2}$ & $10.61 / 10.64$ & $0.62 / 0.65$ & Yes* & High \\
\hline \multirow[t]{2}{*}{$\mathrm{Ba}$} & ${ }^{1} \mathrm{~S}_{0}$ & 0.00 & ${ }^{2} \mathrm{P}_{1 / 2,3 / 2}$ & $11.33 / 11.41$ & $-0.07 /-0.15$ & Yes* & High \\
\hline & ${ }^{3} D_{1,2,3}$ & $1.12 / 1.19$ & ${ }^{2} \mathrm{~S}_{1 / 2}$ & 12.40 & $-0.02 / 0.05$ & Yes & High \\
\hline $\mathrm{Be}$ & ${ }^{1} \mathrm{~S}_{0}$ & 0.00 & ${ }^{2} \mathrm{~S}_{1 / 2}$ & 9.32 & 1.94 & Yes* & Low \\
\hline \multirow[t]{2}{*}{$\mathrm{Ca}$} & ${ }^{1} \mathrm{~S}_{0}$ & 0.00 & ${ }^{2} \mathrm{~S}_{1 / 2}$ & 12.57 & -1.31 & Yes* & Low \\
\hline & ${ }^{3} \mathrm{P}_{0,1,2}$ & $1.88 / 1.90$ & ${ }^{2} D_{3 / 2,5 / 2}$ & 13.16 & $-0.02 / 0.00$ & Yes & High \\
\hline $\mathrm{Cd}$ & ${ }^{1} \mathrm{~S}_{0}$ & 0.00 & ${ }^{2} \mathrm{~S}_{1 / 2}$ & 8.99 & 2.27 & Yes* & Low \\
\hline Co & ${ }^{4} \mathrm{~F}_{9 / 2-3 / 2}$ & $0.00 / 0.22$ & ${ }^{3} \mathrm{D}_{3,2,1}$ & $11.29 / 11.51$ & $-0.25 / 0.19$ & Yes & High \\
\hline \multirow[t]{2}{*}{$\mathrm{Cr}$} & ${ }^{7} \mathrm{~S}_{3}$ & 0.00 & ${ }^{6} \mathrm{~F}_{1 / 2-11 / 2}$ & $12.57 / 12.69$ & $-1.31 /-1.43$ & Yes & Low \\
\hline & ${ }^{5} S_{2}$ & 0.94 & ${ }^{6} \mathrm{~F}_{1 / 2-11 / 2}$ & $12.57 / 12.69$ & $-0.37 /-0.49$ & Yes* & High \\
\hline Cs & ${ }^{2} \mathrm{~S}_{1 / 2}$ & 0.00 & ${ }^{1} \mathrm{~S}_{0}$ & 3.89 & 7.37 & Yes & Low \\
\hline $\mathrm{Eu}$ & ${ }^{8} \mathrm{~S}_{7 / 2}$ & 0.00 & ${ }^{7} S_{1,2,3}$ & $11.82 / 11.98$ & $-0.56 /-0.72$ & Yes & High \\
\hline $\mathrm{Fe}$ & ${ }^{5} \mathrm{D}_{4,3,2,1,0}$ & $0.00 / 0.12$ & ${ }^{4} \mathrm{G}_{11 / 2-5 / 2}$ & $11.05 / 11.13$ & $0.13 / 0.33$ & Yes & High \\
\hline $\mathrm{Ga}$ & ${ }^{2} \mathrm{P}_{1 / 2,3 / 2}$ & $0.00 / 0.10$ & ${ }^{3} \mathrm{P}_{0,1,2}$ & $11.87 / 12.04$ & $-0.78 /-0.51$ & Yes* & High \\
\hline $\mathrm{Ge}$ & ${ }^{3} \mathrm{P}_{0,1,2}$ & $0.00 / 0.17$ & ${ }^{2} \mathrm{P}_{1 / 2,3 / 2}$ & $7.90 / 8.12$ & $3.14 / 3.53$ & Yes & Low \\
\hline In & ${ }^{2} \mathrm{P}_{1 / 2,3 / 2}$ & $0.00 / 0.27$ & ${ }^{3} \mathrm{P}_{0,1,2}$ & $11.03 / 11.47$ & $-0.21 / 0.50$ & Yes* & High \\
\hline K & ${ }^{2} \mathrm{~S}_{1 / 2}$ & 0.00 & ${ }^{1} \mathrm{~S}_{0}$ & 4.34 & 6.92 & Yes & Low \\
\hline $\mathrm{La}$ & ${ }^{2} \mathrm{D}_{3 / 2,5 / 2}$ & $0.00 / 0.13$ & ${ }^{1} \mathrm{P}_{1}$ & 11.24 & $0.02 / 0.15$ & Yes & High \\
\hline $\mathrm{Li}$ & ${ }^{2} S_{1 / 2}$ & 0.00 & ${ }^{1} \mathrm{~S}_{0}$ & 5.39 & 5.87 & Yes & Low \\
\hline $\mathrm{Lu}$ & ${ }^{2} \mathrm{D}_{3 / 2,5 / 2}$ & $0.00 / 0.25$ & ${ }^{1} \mathrm{D}_{2}$ & 11.05 & $0.21 / 0.46$ & Yes & High \\
\hline $\mathrm{Mg}$ & ${ }^{1} \mathrm{~S}_{0}$ & 0.00 & ${ }^{2} \mathrm{P}_{1 / 2,3 / 2}$ & $12.07 / 12.08$ & $-0.81 /-0.82$ & Yes* & High \\
\hline \multirow[t]{2}{*}{ Mn } & ${ }^{6} \mathrm{~S}_{5 / 2}$ & 0.00 & ${ }^{5} \mathrm{D}_{4,0,1,3,2}$ & $11.50 / 11.51$ & $-0.24 /-0.25$ & Yes & High \\
\hline & ${ }^{6} \mathrm{~S}_{5 / 2}$ & 0.00 & ${ }^{7} \mathrm{P}_{2,3,4}$ & $12.19 / 12.24$ & $-0.93 /-0.98$ & Yes* & High \\
\hline \multirow[t]{3}{*}{ Mo } & ${ }^{7} S_{3}$ & 0.00 & ${ }^{6} \mathrm{~F}_{1 / 2-11 / 2}$ & $12.77 / 13.16$ & $-1.51 /-1.90$ & Yes & Low \\
\hline & ${ }^{5} S_{2}$ & 1.34 & ${ }^{6} \mathrm{~F}_{1 / 2-11 / 2}$ & $12.77 / 13.16$ & $-0.17 /-0.56$ & Yes* & High \\
\hline & ${ }^{5} S_{2}$ & 1.34 & ${ }^{4} \mathrm{P}_{1 / 2-5 / 2}$ & $12.94 / 13.15$ & $-0.34 /-0.55$ & Yes & High \\
\hline $\mathrm{Na}$ & ${ }^{2} S_{1 / 2}$ & 0.00 & ${ }^{1} \mathrm{~S}_{0}$ & 5.14 & 6.12 & Yes & Low \\
\hline $\mathrm{Nb}$ & ${ }^{6} \mathrm{D}_{1 / 2-9 / 2}$ & $0.00 / 0.13$ & ${ }^{5} F_{1,2,3,4,5}$ & $11.31 / 11.47$ & $-0.21 / 0.08$ & Yes & High \\
\hline $\mathrm{Ni}$ & ${ }^{3} \mathrm{~F}_{4,3,2}$ & $0.00 / 0.27$ & ${ }^{2} \mathrm{P}_{3 / 2,1 / 2}$ & $11.24 / 11.31$ & $-0.05 / 0.29$ & Yes & High \\
\hline $\mathrm{Pb}$ & ${ }^{3} \mathrm{P}_{0}$ & 0.00 & ${ }^{2} \mathrm{P}_{1 / 2,3 / 2}$ & $7.42 / 9.16$ & $3.84 / 2.10$ & Yes & Low \\
\hline $\mathrm{Pd}$ & ${ }^{1} \mathrm{~S}_{0}$ & 0.00 & ${ }^{2} \mathrm{~F}_{7 / 2,5 / 2}$ & $12.34 / 12.61$ & $-1.35 /-1.08$ & Yes* & High \\
\hline Pt & ${ }^{3} \mathrm{D}_{3,2,1}$ & $0.00 / 1.26$ & ${ }^{2} \mathrm{~F}_{7 / 2,5 / 2}$ & $11.20 / 11.87$ & $-0.61 / 1.32$ & Yes & High \\
\hline \multirow[t]{2}{*}{$\operatorname{Re}$} & ${ }^{6} \mathrm{~S}_{5 / 2}$ & 0.00 & ${ }^{5} S_{2}$ & 9.96 & 1.30 & Yes & Low \\
\hline & ${ }^{6} \mathrm{~S}_{5 / 2}$ & 0.00 & ${ }^{5} \mathrm{P}_{3,2,1}$ & $10.51 / 10.77$ & $0.75 / 0.49$ & Yes & High \\
\hline $\mathrm{Rh}$ & ${ }^{4} \mathrm{~F}_{9 / 2-3 / 2}$ & $0.00 / 0.43$ & ${ }^{3} \mathrm{G}_{5,4,3}$ & $11.39 / 11.66$ & $-0.40 / 0.30$ & Yes & High \\
\hline S & ${ }^{3} \mathrm{P}_{2,1,0}$ & 0.00 & ${ }^{2} D_{3 / 2,5 / 2}$ & 12.20 & -0.94 & Yes & High \\
\hline \multirow[t]{2}{*}{$\mathrm{Sb}$} & ${ }^{4} S_{3 / 2}$ & 0.00 & ${ }^{3} \mathrm{P}_{0,1,2}$ & $8.60 / 9.30$ & $1.96 / 2.66$ & Yes & Low \\
\hline & ${ }^{2} \mathrm{D}_{3 / 2,5 / 2}$ & $1.05 / 1.22$ & ${ }^{1} \mathrm{~S}_{0}, 1,2$ & 11.57 & $0.74 / 0.91$ & Yes & High \\
\hline $\mathrm{Sc}$ & ${ }^{2} \mathrm{D}_{3 / 2,5 / 2}$ & $0.00 / 0.02$ & ${ }^{1} \mathrm{~F}_{3}$ & 10.57 & $0.69 / 0.71$ & Yes & High \\
\hline Sn & ${ }^{3} \mathrm{P}_{0,1,2}$ & $0.00 / 0.42$ & ${ }^{4} \mathrm{P}_{1 / 2,3 / 2.5 / 2}$ & $13.10 / 13.63$ & $-2.37 /-1.42$ & Yes* & Low \\
\hline $\mathrm{Sr}$ & ${ }^{1} \mathrm{~S}_{0}$ & 0.00 & ${ }^{2} S_{1 / 2}$ & 11.60 & -0.34 & Yes* & High \\
\hline $\mathrm{Ti}$ & ${ }^{3} \mathrm{~F}_{2,3,4}$ & $0.00 / 0.05$ & ${ }^{2} \mathrm{G}_{7 / 2,9 / 2}$ & $11.11 / 11.14$ & $0.12 / 0.20$ & Yes & High \\
\hline V & ${ }^{4} \mathrm{~F}_{3 / 2-9 / 2}$ & $0.00 / 0.07$ & ${ }^{3} \mathrm{~F}_{2,3,4}$ & $11.45 / 11.52$ & $-0.26 /-0.12$ & Yes & High \\
\hline $\mathrm{Y}$ & ${ }^{2} \mathrm{D}_{3 / 2,5 / 2}$ & $0.00 / 0.07$ & ${ }^{1} \mathrm{~F}_{3}$ & 10.35 & $0.91 / 0.98$ & Yes & High \\
\hline $\mathrm{Zr}$ & ${ }^{3} \mathrm{~F}_{2,3,4}$ & $0.00 / 0.15$ & ${ }^{2} \mathrm{G}_{7 / 2,9 / 2}$ & $10.91 / 10.99$ & $0.27 / 0.50$ & Yes & High \\
\hline
\end{tabular}

Intermediate interpretation of Wigner's spin rule.

Table 5

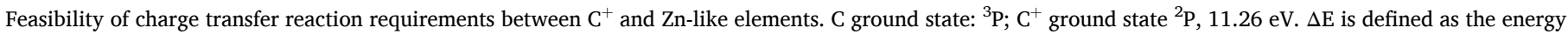
defect between the particle that transfer the charge $\left(\mathrm{C}^{+}\right)$and the sum of the ionization and excitation potentials of the analyte ion generated $\left(\left(\mathrm{M}^{+}\right)^{*}\right)$.

\begin{tabular}{|c|c|c|c|c|c|c|c|}
\hline \multirow[t]{2}{*}{ Analyte } & \multicolumn{2}{|c|}{ Atom electronic level } & \multicolumn{2}{|c|}{ Ion electronic level } & \multirow[t]{2}{*}{$\Delta \mathrm{E}(\mathrm{eV})$} & \multirow[t]{2}{*}{ Spin conservation } & \multirow[t]{2}{*}{ CT probability } \\
\hline & Term & Energy (eV) & Term & Energy (eV) & & & \\
\hline \multirow[t]{2}{*}{$\mathrm{Au}$} & ${ }^{2} S_{1 / 2}$ & 0.00 & ${ }^{1} \mathrm{D}_{2}$ & 12.89 & -1.63 & Yes & Low \\
\hline & ${ }^{2} \mathrm{~S}_{1 / 2}$ & 0.00 & ${ }^{3} \mathrm{D}_{3,2,1}$ & $11.08 / 12.66$ & $-1.4 / 0.18$ & Yes* & High \\
\hline $\mathrm{Cu}$ & ${ }^{2} \mathrm{~S}_{1 / 2}$ & 0.00 & ${ }^{1} \mathrm{D}_{2}$ & 10.99 & 0.27 & Yes & High \\
\hline Gd & ${ }^{9} \mathrm{D}_{2,3,4,5,6}$ & $0.00 / 0.21$ & ${ }^{8} \mathrm{P}_{9 / 2,7 / 2,5 / 2}$ & $12.23 / 12.29$ & $-0.76 /-1.03$ & Yes & High \\
\hline Ir & ${ }^{4} \mathrm{~F}_{9 / 2,3 / 2,5 / 2,7 / 2}$ & $0.00 / 0.78$ & ${ }^{3} \mathrm{P}_{2,1}$ & $11.32 / 11.50$ & $-0.24 / 0.72$ & Yes & High \\
\hline $\mathrm{Zn}$ & ${ }^{1} \mathrm{~S}_{0}$ & 0.00 & ${ }^{2} \mathrm{~S}_{1 / 2}$ & 9.39 & 1.87 & Yes* & Low \\
\hline
\end{tabular}

* Intermediate interpretation of Wigner's spin rule.

sensitive enough for detecting changes in analyte excitation and ionization mechanisms by carbon.

When operating the $\mathrm{Mg}$ II $280.270 \mathrm{~nm} / \mathrm{Mg}$ I $285.213 \mathrm{~nm}$ ratio, however, a $10 \%$ increase in the Mg II $280.270 \mathrm{~nm} / \mathrm{Mg}$ I $285.213 \mathrm{~nm}$ ratio was obtained for the carbon matrix regarding the $1.0 \% \mathrm{w} \mathrm{w}^{-1}$ $\mathrm{HNO}_{3}$ solution. Consequently, the $\mathrm{Mg}$ II $280.270 \mathrm{~nm} / \mathrm{Mg}$ I $285.213 \mathrm{~nm}$ ratio is highly sensitive to carbon matrix effects, but care must be taken to interpret the changes produced in this parameter. The increase in the 
Table 6

Influence of the matrix composition on the values of different plasma excitationrelated parameters. Uncertainties for $\mathrm{I}_{\text {rel }}$ values are presented as the standard deviation of 3 replicates.

\begin{tabular}{lll}
\hline Parameter & \multicolumn{2}{l}{ Matrix } \\
\cline { 2 - 3 } & $\mathrm{HNO}_{3} 1 \% \mathrm{w} \mathrm{w}^{-1}$ & Carbon $20 \mathrm{~g} \mathrm{~L}^{-1}$ \\
\hline Excitation temperature $\left(\mathrm{T}_{\mathrm{ex}}\right)(\mathrm{K}):$ & $7800 \pm 200$ & $7600 \pm 200$ \\
$\quad$ Fe atomic lines & $8300 \pm 200$ & $8400 \pm 200$ \\
Fe ionic lines & $7500 \pm 300$ & $7800 \pm 300$ \\
Ti atomic lines & $7100 \pm 300$ & $7200 \pm 300$ \\
$\quad$ Ti ionic lines & & \\
Ionic to atomic ratio & & \\
$\mathrm{Mg}$ II $(280.270 \mathrm{~nm}) / \mathrm{Mg} \mathrm{I}(285.213 \mathrm{~nm})$ & $5.20 \pm 0.03$ & $5.70 \pm 0.02$ \\
\hline
\end{tabular}

ionic to atomic line intensity ratio would suggest that plasma excitation conditions are enhanced due to the presence of carbon (i.e., higher plasma temperature). However, the higher $\mathrm{Mg}$ II $280.270 \mathrm{~nm} / \mathrm{Mg} \mathrm{I}$ $285.213 \mathrm{~nm}$ ratio observed for the glycerol solutions was due to signal suppression of atomic lines rather than an increase on ionic emission. It should be kept in mind that neither the shape and position of the discharge (i.e., thermal pinch [44]) nor the Ar I $430.010 \mathrm{~nm}$ line to Ar continuum ratio were affected by glycerol introduction.

\subsubsection{Influence of the carbon source on matrix effects}

Unlike glycerol at the concentration level employed in this work, most of the carbon-rich matrices analysed in ICP-OES strongly affect, in addition, both aerosol and plasma characteristics (e.g. acetic acid, ethanol, xylene, etc.) [1,4-7]. Therefore, when using this kind of organics, the magnitude of carbon matrix effects may vary significantly with regard glycerol solutions. To investigate carbon matrix effects on the emission of atomic lines operating such kind of matrices, analyte emission signals for a $20 \mathrm{~g} \mathrm{~L}^{-1} \mathrm{C}$ solution made from acetic acid were compared with those obtained with $1.0 \% \mathrm{w} \mathrm{w}^{-1} \mathrm{HNO}_{3}$. Fig. 6 shows $\mathrm{I}_{\text {rel }}$ values obtained for different $\mathrm{Mg}$ and As atomic emission lines according to their $\mathrm{E}_{\text {upper level }}$ for both acetic and glycerol solutions. It is observed that, regardless the matrix considered, $\mathrm{I}_{\text {rel }}$ values for $\mathrm{Mg}$ and As atomic

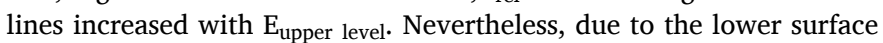
tension of the acetic acid, [5] $\mathrm{I}_{\text {rel }}$ values for this matrix were significantly higher than those obtained with glycerol, irrespective of the analyte and line tested. Similar findings were observed for all the elements and lines studied in this work. From data shown in Fig. 6 for acetic acid, it could be concluded that the emission of $\mathrm{Mg}$ atomic lines was not affected by carbon whereas As atomic lines showed higher (positive) matrix effects. According to these results, when other factors come into play (e.g. aerosol generation, etc.), the influence of carbon on the analyte atomic

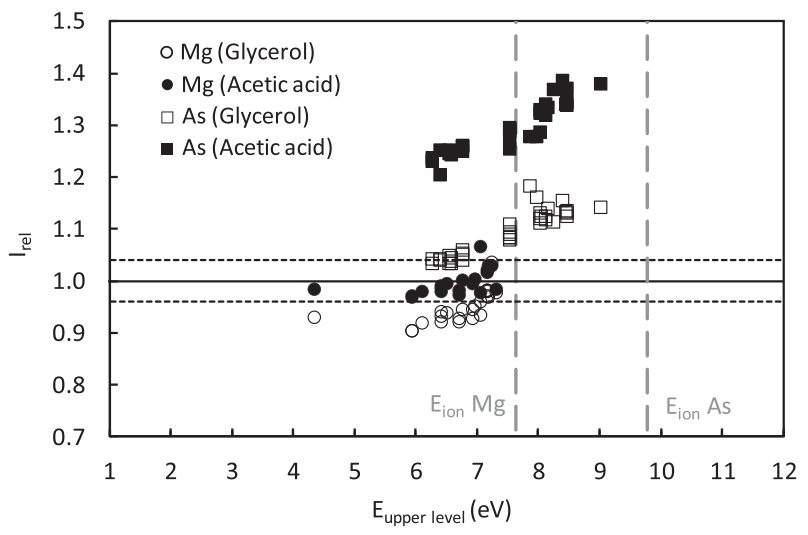

Fig. 6. Relative signal intensity ( $\mathrm{I}_{\text {rel }}$ ) obtained for $\mathrm{Mg}$ and As atomic lines operating a $20 \mathrm{~g} \mathrm{~L}^{-1}$ carbon containing solution prepared with acetic acid or glycerol. $I_{\text {rel }}$ values among horizontal dotted lines indicate no measurable matrix effects within the experimental uncertainties. population (and hence, on the emission signal) might be challenging to notice unless plasma robustness is checked (i.e., $\mathrm{Mg}$ II $280.270 \mathrm{~nm} / \mathrm{Mg} \mathrm{I}$ $285.213 \mathrm{~nm})$.

\subsubsection{Analyte emission wavelength selection}

In some cases, carbon matrix effects in ICP-OES would not present a serious problem for metal analysis since ionic lines are usually selected to maximize detection capabilities due to its higher sensitivity against the atomic ones. Nevertheless, Ag, Al, As, Au, B, Cs, Cu, Ga, Ge, Hg, I, In, $\mathrm{K}, \mathrm{Li}, \mathrm{Na}, \mathrm{P}, \mathrm{Pb}, \mathrm{Pd}, \mathrm{Rh}, \mathrm{S}, \mathrm{Sb}, \mathrm{Se}, \mathrm{Sn}$, Te and $\mathrm{Zn}$ constitutes the exception of this rule. For these elements, atomic lines are most sensitive than the ionic ones and, then, the presence of carbon might significantly affect the accuracy of the results.

To evaluate carbon matrix effects on the emission signal of the most sensitive wavelength for the above-mentioned elements in real sample analysis, different carbon-containing samples (e.g., mussel tissue, fly ashes, polyethylene and seagrasses) were digested (Table S3, Appendix) to know the carbon concentration levels present in the final sample solution. The amount of carbon was estimated by measuring the C I $193.030 \mathrm{~nm}$ emission line signal in sample digests using glycerol standards (i.e., $1-20 \mathrm{~g} \mathrm{~L}^{-1} \mathrm{C}$ ). The carbon content found in the different samples ranges from $0.2 \mathrm{~g} \mathrm{~L}^{-1}$ (polyethylene) to $5 \mathrm{~g} \mathrm{~L}^{-1}$ (Posidonia oceanica (L.) Delile). Therefore, the latter carbon concentration was selected to evaluate matrix effects on the most sensitive wavelength of Ag, Al, As, Au, B, Cs, Cu, Ga, Ge, Hg, I, In, K, Li, Na, P, Pb, Pd, Rh, S, Sb, $\mathrm{Se}, \mathrm{Sn}, \mathrm{Te}$ and $\mathrm{Zn}$ (Table 7). In general, no measurable matrix effects within the experimental uncertainties were noticed for Ag, Al, As, Au, B, $\mathrm{Cu}, \mathrm{Ga}, \mathrm{Ge}, \mathrm{Hg}, \mathrm{I}, \mathrm{In}, \mathrm{P}, \mathrm{Pb}, \mathrm{Pd}, \mathrm{Rh}, \mathrm{S}, \mathrm{Sb}, \mathrm{Sn}, \mathrm{Te}$ and $\mathrm{Zn}$. However, significant signal suppression ( $>10 \%$ ) was observed for $\mathrm{Cs}, \mathrm{K}, \mathrm{Li}$ and $\mathrm{Na}$ atomic lines. Also, a signal enhancement of about $12 \%$ was observed for Se. From these results, it can be concluded that accuracy for alkali elements and Se can be compromised due to presence of residual carbon after acid digestion treatments. Nevertheless, these conclusions should be revised when the residual carbon concentration would be higher than $5 \mathrm{~g} \mathrm{~L}^{-1}$, since matrix effects for a higher number of elements would be expected. To mitigate carbon matrix effects on elemental analysis by means of ICP-OES, different approaches are feasible: (i) matrix

Table 7

Relative intensity ratio $\left(\mathrm{I}_{\text {rel }}\right)$ for atomic emission lines of the elements selected operating a Carbon $5 \mathrm{~g} \mathrm{~L}^{-1}$ solution. Wavelengths included correspond to the most sensitive line of each element. Uncertainties for $\mathrm{I}_{\text {rel }}$ values are presented as the standard deviation of 3 replicates.

\begin{tabular}{lllll}
\hline Element & Wavelength $(\mathrm{nm})$ & $\mathrm{E}_{\text {upper level }}(\mathrm{eV})$ & $\mathrm{E}_{\text {ion }}(\mathrm{eV})$ & $\mathrm{I}_{\text {rel }}$ \\
\hline $\mathrm{K}$ & 766.491 & 1.62 & 4.34 & $0.90 \pm 0.02$ \\
$\mathrm{Na}$ & 588.995 & 2.10 & 5.14 & $0.88 \pm 0.02$ \\
$\mathrm{In}$ & 451.131 & 3.02 & 5.79 & $0.96 \pm 0.03$ \\
$\mathrm{Al}$ & 396.152 & 3.14 & 5.98 & $0.95 \pm 0.02$ \\
$\mathrm{Cs}$ & 672.328 & 3.23 & 3.89 & $0.82 \pm 0.03$ \\
$\mathrm{Rh}$ & 343.488 & 3.61 & 7.46 & $0.95 \pm 0.03$ \\
$\mathrm{Ag}$ & 328.068 & 3.78 & 7.58 & $0.97 \pm 0.03$ \\
$\mathrm{Cu}$ & 327.395 & 3.79 & 7.73 & $1.01 \pm 0.04$ \\
$\mathrm{Li}$ & 610.365 & 3.88 & 5.39 & $0.90 \pm 0.01$ \\
$\mathrm{Ga}$ & 294.363 & 4.31 & 6.00 & $0.97 \pm 0.02$ \\
$\mathrm{~Pb}$ & 283.305 & 4.37 & 7.41 & $0.99 \pm 0.03$ \\
$\mathrm{Pd}$ & 340.458 & 4.45 & 8.34 & $1.04 \pm 0.02$ \\
$\mathrm{Sn}$ & 283.998 & 4.79 & 7.34 & $1.00 \pm 0.01$ \\
$\mathrm{Ge}$ & 265.117 & 4.85 & 7.90 & $0.98 \pm 0.03$ \\
$\mathrm{Hg}$ & 253.652 & 4.89 & 10.44 & $1.03 \pm 0.02$ \\
$\mathrm{~B}$ & 249.772 & 4.96 & 8.29 & $1.02 \pm 0.02$ \\
$\mathrm{Au}$ & 242.794 & 5.10 & 9.22 & $1.01 \pm 0.02$ \\
$\mathrm{Sb}$ & 217.582 & 5.70 & 8.61 & $0.98 \pm 0.03$ \\
$\mathrm{Te}$ & 217.582 & 5.70 & 8.61 & $0.98 \pm 0.03$ \\
$\mathrm{Zn}$ & 213.857 & 5.80 & 9.39 & $0.99 \pm 0.01$ \\
$\mathrm{Se}$ & 196.026 & 6.32 & 9.75 & $1.12 \pm 0.03$ \\
$\mathrm{As}$ & 188.980 & 6.56 & 9.78 & $1.03 \pm 0.03$ \\
$\mathrm{~S}$ & 181.972 & 6.86 & 10.36 & $1.01 \pm 0.02$ \\
$\mathrm{I}$ & 178.215 & 6.95 & 10.45 & $0.99 \pm 0.03$ \\
$\mathrm{P}$ & 213.618 & 7.21 & 10.49 & $1.01 \pm 0.02$ \\
\hline & & & &
\end{tabular}


matching; (ii) buffering matrix effects with the addition of a high carbon concentration to both standard and samples [10]; (iii) internal standardization; and (iv) standard addition calibration method. In this case, internal standard wavelength should be carefully selected according to both analyte $\mathrm{E}_{\text {ion }}$ and atomic wavelength $\mathrm{E}_{\text {upper level }}$ (Table S2, Appendix). Nevertheless, given the potential influence of other concomitants present in the sample, the suitability of a given internal standard should be checked for any specific application.

\section{Conclusions}

Results in this work clearly show that carbon matrix effects on the emission signal of atomic lines in ICP-OES are rather complex. In general, signal enhancement effects occur for atomic lines of As, B, Hg, I, P, Se and Te whereas signal suppression prevails among atomic lines of $\mathrm{Ag}$, $\mathrm{Al}, \mathrm{Be}, \mathrm{Ba}, \mathrm{Ca}, \mathrm{Cd}, \mathrm{Co}, \mathrm{Cr}, \mathrm{Cs}, \mathrm{Eu}, \mathrm{Fe}, \mathrm{Ga}, \mathrm{Ge}, \mathrm{K}, \mathrm{Ho}$, In, La, Li, Lu, Mg, Mn, Mo, Na, Nb, Ni, Pb, Pd, Pr, Pt, Re, Rh, S, Sb, Sc, Sn, Sr, Ti, Tm, V, Y and Zr. No measurable matrix effects within experimental uncertainties are registered for $\mathrm{Au}, \mathrm{Cu}, \mathrm{Ir}, \mathrm{Gd}$ and $\mathrm{Zn}$ atomic lines. As regards Ce, Dy, Er, $\mathrm{Nd}, \mathrm{Sm}, \mathrm{Tb}, \mathrm{Th}, \mathrm{U}$ and $\mathrm{Yb}$ no clear conclusion about matrix effects is feasible due to the limited atomic emission wavelengths monitored. Experimental data suggest that the presence of carbon in the sample matrix affects both analyte ionic and atomic populations through different carbon-based mechanisms: (i) CT reactions; (ii) collisional ionization; and (iii) collisional excitation. To further insight into the specific contribution of each of the above-mentioned to matrix effects as well as the discrepancies observed on matrix effects for some elements between ICP-AES and ICP-MS (e.g. Au), additional experiments using an ad hoc (i.e., custom made) experimental setup would be required [35]. Some practical considerations can be derived from these findings. First, the use of $\mathrm{Mg}$ II/Mg I to evaluate plasma robustness is highly sensitive to carbon non-spectral interferences due to the different matrix effects affecting atomic and ionic lines of a given element. Carbon source also plays an important role in the intensity of matrix effects, since the emission of atomic lines could be affected by changes on the excitation and ionization mechanisms but also on the aerosol generation and transport to the plasma. Finally, a judicious selection of the analyte wavelength must be performed to avoid carbon-based matrix effects, particularly for Se and alkali elements. On this regard, the selection of the internal standard is not a trivial task since it must take into account both analyte and wavelength characteristics (i.e., $\mathrm{E}_{\text {ion }}$ and $\mathrm{E}_{\text {upper level). }}$ ).

\section{Declaration of Competing Interest}

The authors declare that they have no known competing financial interests or personal relationships that could have appeared to influence the work reported in this paper.

\section{Acknowledgements}

Authors would like to express their appreciation to the University of Alicante (Projects VIGROB-050, UADIF17-42 and UAUSTI16-02) for financial support. Authors also thank all the comments and suggestions provided by the reviewers for improving discussion about carbon-based CT reactions.

\section{Appendix A. Supplementary data}

Supplementary data to this article can be found online at https://doi. org/10.1016/j.sab.2021.106070.

\section{References}

[1] A. Leclerq, A. Nonell, J.L. Todolí, C. Bresson, L. Vio, T. Vercouter, F. Chartier, Introduction of organic/hydro-organic matrices in inductively coupled plasma optical emission spectrometry and mass spectrometry: a tutorial review. Part I. Theoretical considerations, Anal. Chim. Acta 885 (2015) 33-56.
[2] A. Leclerq, A. Nonell, J.L. Todolí, C. Bresson, L. Vio, T. Vercouter, F. Chartier, Introduction of organic/hydro-organic matrices in inductively coupled plasma optical emission spectrometry and mass spectrometry: a tutorial review. Part II. Practical considerations, Anal. Chim. Acta 885 (2015) 57-91.

[3] G. Grindlay, J. Mora, M.T.C. de Loos-Vollebregt, F. Vanhaecke, Evaluation of the multi-element capabilities of collision/reaction cell inductively coupled plasma-mass spectrometry in wine analysis, Talanta 128 (2014) 379-385.

[4] D. Martínez, D. Torregrosa, G. Grindlay, L. Gras, J. Mora, Coupling dispersive liquid-liquid microextraction to inductively coupled plasma atomic emission spectrometry: an oxymoron? Talanta 176 (2018) 374-381.

[5] G. Grindlay, S. Maestre, L. Gras, J. Mora, Introduction of organic solvent solutions into inductively coupled plasma-atomic emission spectrometry using a microwave assisted sample introduction system, J. Anal. At. Spectrom. 21 (2006) 1403-1411.

[6] Z. Hu, S. Hu, S. Gao, Y. Liu, S. Lin, Volatile organic solvent-induced signal enhancements in inductively coupled plasma-mass spectrometry: a case study of methanol and acetone, Spectrochim. Acta Part B 59 (2004) 1463-1470.

[7] M. Kovačevič, W. goessler, Direct introduction of volatile carbon compounds into the spray chamber of an inductively coupled plasma mass spectrometer: sensitivity enhancement for selenium, Spectrochim. Acta Part B 60 (2005) 1357-1362.

[8] G. Grindlay, J. Mora, M.T.C. de Loos-vollebregt, F. Vanhaecke, A systematic study on the influence of carbon on the behavior of hard-to-ionize elements in inductively coupled plasma - mass spectrometry, Spectrochim. Acta Part B 86 (2013) 42-49.

[9] E.H. Larsen, S. Stürup, Carbon-enhanced inductively coupled plasma mass spectrometric detection of arsenic and selenium and its application to arsenic speciation, J. Anal. At. Spectrom. 9 (1994) 1099-1105.

[10] G. Grindlay, L. Gras, J. Mora, M.T.C. de Loos-vollebregt, Carbon-related matrix effects in inductively coupled plasma atomic emission spectrometry, Spectrochim. Acta Part B 63 (2008) 234-243.

[11] J. Machat, V. Otruba, V. Kanicky, Spectral and non-spectral interferences in the determination of selenium by inductively coupled plasma atomic emission spectrometry, J. Anal. At. Spectrom. 17 (2002) 1096-1102.

[12] G. Grindlay, L. Gras, J. Mora, M.T.C. de Loos-vollebregt, Carbon-, sulfur-, and phosphorus-based charge transfer reactions in inductively coupled plasma - atomic emission spectrometry, Spectrochim. Acta Part B 115 (2016) 8-15.

[13] H. Wiltsche, M. Winkler, P. Tirk, Matrix effects of carbon and bromine in inductively coupled plasma optical emission spectrometry, J. Anal. At. Spectrom. 30 (2015) 2223-2234.

[14] P. Allain, L. Jaunault, Y. Mauras, J.M. Mermet, T. Delaporte, Signal enhancement of elements due to the presence of carbon-containing compounds in inductively coupled plasma mass spectrometry, Anal. Chem. 63 (1991) 1497-1498.

[15] T. Nakazawa, D. Suzuki, H. Sakuma, N. Furuta, Comparison of signal enhancement by co-existing carbon and by co-existing bromine in inductively coupled plasma mass spectrometry, J. Anal. At. Spectrom. 29 (2014) 1299-1305.

[16] G.C. Chan, G.M. Hieftje, Using matrix effects as a probe for the study of the chargetransfer mechanism in inductively coupled plasma-atomic emission spectrometry, Spectrochim. Acta Part B 59 (2004) 163-183.

[17] G.C.Y. Chan, G.M. Hieftje, Experimental evidence of state-selective charge transfer in inductively coupled plasma-atomic emission spectrometry, Spectrochim. Acta Part B 59 (2004) 1007-1020.

[18] P.B. Farnsworth, A. Woolley, N. Omenetto, O. Matveev, Experimental studies of charge transfer reactions between argon and the third row metals calcium through copper in the inductively coupled plasma, Spectrochim. Acta Part B 54 (1999) 2143-2155.

[19] G.L. Long, J.S. Bolton, The effect of propane on atomic spectrometric signals in the inductively coupled argon plasma, Spectrochim. Acta Part B 42 (1987) 581-589.

[20] NIST atomic spectra database (Version 5) (Last access August 2019), https://ph ysics.nist.gov/PhysRefData/ASD/lines_form.html, 2019.

[21] Atomic line list (Version 2.04) (Last access August 2019), http://www.pa.uky. edu/ peter/atomic/, 2019.

[22] Atomic spectral line database (Last access August 2019), http://www.pmp.uni-h annover.de/cgi-bin/ssi/test/kurucz/sekur.html, 2019.

[23] J.E. Sansonetti, W.C. Martin, Handbook of basic atomic spectroscopic data, J. Phys. Chem. Ref. Data 34 (2005) 1559-2259.

[24] A. Batal, J. Jarosz, J.M. Mermet, A spectrometric study of a $40 \mathrm{MHz}$ inductively coupled plasma-VI. Argon continuum in the visible region of the spectrum, Spectrochim. Acta Part B 36 (1981) 983-992.

[25] R.S. Houk, Mass spectrometry of inductively coupled plasmas, Anal. Chem. 58 (1986) 97-105.

[26] S.A. Lehn, G.M. Hieftje, Experimental evaluation of analyte excitation mechanisms in the inductively coupled plasma, Spectrochim. Acta Part B 58 (2003) 1821-1836.

[27] K. Wagatsuma, K. Satoh, Estimation using an enhancement factor on non local thermodynamic equilibrium behavior of high-lying energy levels of neutral atom in argon radio-frequency inductively-coupled plasma, Anal. Sci. 32 (2016) 535-541.

[28] C.S. Enos, A.G. Brenton, A.R. Lee, A unified view of the spin conservation rule for disparate collisional processes, Int. J.Mass Spectrom. Ion Process. 122 (1992) $361-376$.

[29] P.B. Farnsworth, B.W. Smith, N. Omenetto, An investigation of the balance of charge-exchange between $\mathrm{Mg}$ and Ar ions in the ICP, Spectrochim. Acta Part B 46 (1991) 843-850.

[30] P.B. Farnsworth, N. Omenetto, The kinetics of charge-exchange between argon and magnesium in the inductively-coupled plasma, Spectrochim. Acta Part B 48 (1993) 809-816.

[31] K. Wagatsuma, K. Hirokawa, Classification of singly ionized iron emission lines in the 160-250 nm wavelength region from grimm-type glow discharge plasma, Spectrochim. Acta Part B 51 (1996) 349-374. 
[32] E.B.M. Steers, A.P. Thorne, Application of high-resolution Fourier transform spectrometry to the study of glow discharge sources: part 1. Excitation of iron and chromium spectra in a microwave boosted glow discharge source, J. Anal. At. Spectrosc. 8 (1993) 309-315.

[33] Z. Weiss, E.B.M. Steers, J.C. Pickering, S. Mushtaq, Transition rate diagrams - A new approach to the study of selective excitation processes: the spectrum of manganese in a Grimm-type glow discharge, Spectrochim. Acta Part B 92 (2014) 70-83.

[34] D.R. Lide, CRC Handbook of Chemistry and Physics, CRC Press, Boca Raton, FL, 2005.

[35] N. Taylor, K.N. McKay-Bishop, R.L. Spencer, P.B. Farnsworth, A novel approach to understanding the effect of matrix composition on analyte emission in an inductively coupled plasma, J. Anal. At. Spectrom. 29 (2014) 644-656.

[36] G.C.Y. Chan, G.M. Hieftje, Investigation of plasma-related matrix effects in inductively coupled plasma-atomic emission spectrometry caused by matrices with low second ionization potentials-identification of the secondary factor, Spectrochim. Acta Part B 61 (2006) 642-659.

[37] J.-M. Mermet, Fundamental principles of inductively coupled plasmas, in: S.J. Hil (Ed.), Inductively Coupled Plasma Spectrom and its applications, Academic Press Ltd., Sheffield, 2002, p. 35.
[38] G.J. Bastiaans, R.A. Mangold, The calculation of electron density and temperature in Ar spectroscopic plasmas from continuum and line spectra, Spectrochim. Acta Part B 40 (1985) 885-892.

[39] J.F. Alder, R.M. Bombelka, G.G. Kirkbright, Electronic excitation and ionization temperature measurements in a high frequency inductively coupled argon plasma source and the influence of water vapour on plasma parameters, Spectrochim. Acta Part B 35 (1980) 163-175.

[40] J.R. Fuhr, W.L. Wiese, A critical compilation of atomic transition probabilities for neutral and singly ionized iron, J. Phys. Chem. Ref. Data 35 (2006) 1669-1809.

[41] W.L. Wiese, J.R. Fuhr, Atomic transition probabilities for scandium and titanium (A critical data compilation of allowed lines), J. Phys. Chem. Ref. Data 4 (1975) 263-352.

[42] J.M. Mermet, Use of magnesium as test element for inductively coupled plasma atomic emission spectrometry diagnostics, Anal. Chim. Acta 250 (1991) 85-94.

[43] I.B. Brenner, A.T. Zander, Axially and radially viewed inductively coupled plasmas - a critical review, Spectrochim. Acta Part B 55 (2000) 1195-1240.

[44] D.G. Weir, M.W. Blades, Characteristics of an inductively coupled argon plasma operating with organic aerosols. Part 1. Spectral and spatial observations, J. Anal. At. Spectrom. 9 (1994) 1311-1322. 